\title{
Effect of embedded nanoparticle surface chemistry on plasmonic organic photovoltaic devices
}

\author{
Terence K. S. Wong ${ }^{1}$
}

Received: 7 November 2016/ Accepted: 17 January 2017/Published online: 1 February 2017

(c) The Author(s) 2017. This article is published with open access at Springerlink.com

\begin{abstract}
The effect of noble metal nanoparticle (NP) synthesis method on the plasmonic enhancement of organic photovoltaic device performance by these NPs is reviewed. For direct incorporation into a polymer fullerene bulk heterojunction (BHJ) active layer, chemically synthesized colloidal Au or Ag NPs with organic ligands are generally ineffective. Due to the tendency of the ligands in causing exciton quenching, carrier trapping and recombination, the device power conversion efficiency (PCE) can be lower than a BHJ device without NPs. Ligand-free metal NPs prepared by physical methods such as pulsed laser ablation and electron beam evaporation can enhance the PCE when introduced into the BHJ. An alternative effective approach for both polymer and small molecule BHJ devices is core shell metal-silica NPs. Regardless of synthesis method, the NP size should be controlled to the range of $\sim 50-100 \mathrm{~nm}$ to increase light trapping due to scattering and achieve synergistic enhancement. A non-spherical NP morphology with tunable dual localized surface plasmon resonance peaks at visible wavelengths is highly desirable. For core shell metal-silica NPs, the dielectric shell thickness must be optimized to ensure significant localized field enhancement at the surface of the NP.
\end{abstract}

Keywords Organic photovoltaics $\cdot$ Solar cells $\cdot$ Localized surface plasmon resonance $\cdot$ Nanoparticles $\cdot$ Nanorods

Terence K. S. Wong

ekswong@ntu.edu.sg

1 OPTIMUS, School of Electrical and Electronic Engineering, Nanyang Technological University, 50 Nanyang Avenue, Singapore 639798, Singapore

\section{Introduction}

In recent years, OPV devices enhanced by incorporated metallic NP have become one of the most intensively studied topic in OPV research [1,2]. The basic principle behind NP-incorporated OPV devices is the application of the LSPR phenomenon in metallic NP to improve the light trapping and absorption of small molecule and polymer OPV devices which typically have very thin $(\sim 100 \mathrm{~nm})$ absorber layers [3]. The LSPR is a collective oscillation of surface conduction electrons driven by an incident electromagnetic field at the resonance frequency [4, 5]. As a result of the LSPR, the PCE of the plasmonic OPV device can be (but not necessarily always) higher than a conventional BHJ OPV device made from the same donor and acceptor materials. The technique has attracted such interest because the discovery of new hole conducting (ptype) and especially electron conducting (n-type) organic semiconductors has slowed somewhat in recent years. The highest certified PCE for OPV devices at present is $11.5 \%$ $[6,7]$. In the research literature, a current highest PCE of $10.5 \%$ was reported for a low bandgap polymer OPV device [8]. Based on the existing set of organic semiconductors and BHJ device architecture, the PCE is unlikely to significantly exceed the crucial $10 \%$ threshold required for renewable energy application of OPV [9]. It is important to point out at the outset that the introduction of metallic NPs does not alter basic operating principle of OPV devices. The photovoltaic energy conversion still follows the well-established mechanism comprising: (1) sun light absorption, (2) exciton diffusion/dissociation, (3) carrier transport and (4) carrier collection [10, 11]. The metallic NPs primarily enhance the efficiency of the first step so that more excitons are generated within the BHJ layer. 
The use of metallic NP to enhance the performance of optoelectronic devices was first demonstrated by Stuart and Hall [12] in their pioneering work on silicon on insulator (SOI) photodetectors in 1996. This was followed by research on surface plasmon silicon solar cells [13, 14]. The effect of metallic NP on the properties of polymer OPV devices was first investigated by Kim and Caroll [15]. These investigators concluded that the effect of the Au NP was primarily an improvement of the conductivity of the donor in the BHJ. Since then, this work has triggered a great deal of interest within the OPV research community. In the past decade, a large body of literature has been published on plasmonic OPV devices [9, 16, 17]. The focus of the research effort had been mainly about demonstrating the benefits of metallic NPs in facilitating light trapping and absorption. Numerous metallic NP morphologies such as nanosphere, nanorod (NR), nanodisk (ND), nanowire (NW) and their combination have been investigated [18-20]. In addition, the spatial location of the NPs within the OPV device structure has been the subject of much study. NPs have been incorporated into the anode buffer layer (typically poly3,4-ethylene-dioxythiophene:polystyrenesulphonic acid, PEDOT:PSS), the BHJ layer or at the interface of the buffer and BHJ layer [21-23]. Due to the short range nature of the LSPR effect, there are advantages in embedding NPs inside the BHJ itself. For incorporation into the BHJ layer, both small molecule/fullerene and conjugated polymer/fullerene donor acceptor pairs have been studied. Several comprehensive reviews have already been published on these plasmonic OPVs [2, 9, 16, 17]. In general, these prior reviews only discussed the effect of metallic NPs on the PCE of OPV devices when they were added to the device layers. Relatively little experimental data are presented regarding mechanisms, especially on how the enhanced near field around the NP can lead to increased absorption [24]. This could be due to the difficulty of performing in situ characterization on NPs embedded within the active layer.

In this review, we adopt a different perspective and highlight the crucial importance of the metallic NP synthesis method and the surface chemistry of synthesized NPs on the plasmonic OPV device performance. We focus exclusively on the incorporation of NPs in the BHJ layer and the NP synthesis or preparation method. By systematically surveying this subset of the recent plasmonic OPV literature, we can recognize the different effects on device performance when NP of the same noble metal but different surface chemistry is introduced into the absorber layer. For the purpose of this article, metallic NPs are categorized into: (1) NPs with an organic ligand shell, (2) bare NPs and (3) core-shell NPs with an insulating shell. The comparison will be made according to the device photovoltaic parameters, namely the short circuit current density $J_{\mathrm{sc}}$, open circuit voltage $V_{\mathrm{oc}}$, fill factor, FF and PCE. It is useful to review the field of plasmonic OPV in this way because there is at present no consensus on the relative merits of each approach. Some investigators argue that incorporating core shell metallic NPs may adversely affect the charge transport within the BHJ [25]. On the other hand, adding NP with organic ligands into the BHJ has been reported to cause exciton quenching or carrier recombination [16]. Since the same metals ( $\mathrm{Au}$ or $\mathrm{Ag}$ ) are generally used for incorporation, this strongly suggests that the method of preparation has a large influence on the effectiveness of the plasmonic enhancement. To realize high-performance plasmonic OPV, it is also important to have proper guidelines for the synthesis of the metallic NPs with respect to size, shape, dielectric environment, concentration and surface chemistry.

\section{Noble metal NP with organic ligands in BHJ}

\section{Au NP}

As mentioned in the introduction, the positive effect of incorporating noble metal NPs into the active layer of polymer OPV devices was first reported by Kim and Carroll [15]. In this seminal study, $5.3 \mathrm{~nm} \mathrm{Au} \mathrm{stabilized} \mathrm{by}$ long-chain dodecyl amine (DDA, $\mathrm{C}_{12} \mathrm{H}_{25} \mathrm{NH}_{2}$ ) ligands were synthesized by reducing tetrachloroauric acid $\left(\mathrm{HAuCl}_{4}\right)$ in a two-phase water/toluene mixture containing DDA [26]. The reducing agent is sodium borohydride $\left(\mathrm{NaBH}_{4}\right)$. The Au NPs were added into a chlorobenzene solution comprising regio-regular poly(3-octylthiophene) (P3OT) and fullerene $\left(\mathrm{C}_{60}\right)$ at different wt\% of P3OT. NPdoped P3OT: $\mathrm{C}_{60}$ devices were prepared by spin coating the active layer onto the substrate. Dark current voltage (IV) measurements of these devices showed that the main effect of Au NP doping is a reduction in the series resistance $R_{\mathrm{s}}$ compared with the undoped device. When the P3OT: $\mathrm{C}_{60}$ devices were illuminated by $\mathrm{AM} 1.5 \mathrm{G}$ radiation at $80 \mathrm{~mW} /$ $\mathrm{cm}^{2}$, the $J_{\mathrm{sc}}, V_{\mathrm{oc}}, \mathrm{FF}$ and PCE all increased with NP concentration up to $1.7 \mathrm{wt} \%$ for Au NPs. The change in PCE for $\mathrm{Au}$ NP doping relative to the control was 70\%. At a higher level of NP loading, there was a significant drop in the $V_{\mathrm{oc}}$. Both the absorption spectrum and the external quantum efficiency (EQE) spectrum of the doped P3OT: $\mathrm{C}_{60}$ devices did not show a significant increase relative to the undoped device. As a result, the higher PCE in doped devices can only be attributed to increased conductivity of the active layer. It is proposed that Au NP doping resulted in dopant states in the highest occupied molecular orbital (HOMO)-lowest unoccupied molecular orbital (LUMO) gap of P3OT. The hopping transport of 
holes in $\mathrm{P} 3 \mathrm{OT}$ resulting from exciton dissociation at the P3OT: $\mathrm{C}_{60}$ interface was shown to be facilitated by the NP dopant states [15]. This interpretation is consistent with the larger FF observed in P3OT: $\mathrm{C}_{60}$ devices doped with $\mathrm{Au}$ NPs.

Although Au NPs enhance the performance of P3OT: $\mathrm{C}_{60}$ devices, they are generally not beneficial when blended into the BHJ of other polymer OPV devices. Topp et al. [27] systematically investigated the effect of adding colloidal $\mathrm{Au}$ NPs stabilized by different organic ligands into a BHJ layer comprising poly(3-hexylthiophene) P3HT and [6]-phenyl$\mathrm{C}_{61}$-butyric acid methyl ester ( $\left.\mathrm{PC}_{61} \mathrm{BM}\right) \mathrm{OPV}$ devices. $\mathrm{Au}$ NPs with P3HT as ligands were synthesized by first introducing $\mathrm{HAuCl}_{4}$ into toluene using the surfactant tetraoctylammonium bromide. After adding P3HT ligands to the reaction mixture, $\mathrm{NaBH}_{4}$ was added to prepare $\mathrm{P} 3 \mathrm{HT}$ capped $\mathrm{Au}$ NPs at room temperature [28]. The average diameter of these NPs was $3.7 \mathrm{~nm}$. Au NPs with P3HT ligands were blended with $\mathrm{PC}_{61} \mathrm{BM}$ in a 1:1 $\mathrm{P} 3 \mathrm{HT}: \mathrm{PC}_{61} \mathrm{BM}$ weight ratio to fabricate ITO/PEDOT:PSS/Au-P3HT:PC ${ }_{61} \mathrm{BM} / \mathrm{Al} \mathrm{BHJ}$ devices with different amount of $\mathrm{Au}$ in the active layer. (The amount of Au is expressed as the weight \% of Au in the $\mathrm{Au}-$ P3HT NPs.) Although these devices showed a photovoltaic response, their PCE was lower than that of reference cells without Au-P3HT NPs due to lower $V_{\mathrm{oc}}, J_{\mathrm{sc}}$ and FF. For the device with $3 \mathrm{wt} \%$ Au NPs, the PCE was 1.5 versus $2.5 \%$ for the reference cell. A further increase of Au NPs to $16 \%$ resulted in a PCE of only $0.4 \%$ [27].

Topp et al. also studied Au NPs stabilized by DDA that were synthesized by the method of Jana and Peng [29]. This single phase synthesis involved first dissolving DDA and gold trichloride $\left(\mathrm{AuCl}_{3}\right)$ in toluene with the aid of the surfactant didodecyldimethylammonium bromide (DDAB) and ultrasonication [27]. Next, the reducing agent tetrabutylammonium borohydride (TBAB) dissolved in toluene containing $\mathrm{DDAB}$ was added to the $\mathrm{AuCl}_{3}$ solution. Note that both the starting reagents and solvents are different from those used by Kim and Carroll [15]. Au-DDA NPs with a diameter of $7.0 \mathrm{~nm}$ and a much narrower size distribution than that in ref [15] were formed. Au NPs with DDA ligands were dissolved in chlorobenzene and added directly to a solution of P3HT: $\mathrm{PC}_{61} \mathrm{BM}$. For an active layer containing $3 \mathrm{wt} \% \mathrm{Au}$ (with reference to weight of $\mathrm{P} 3 \mathrm{HT}$ ), the PCE was found to be $2.9 \%$. This was lower than the PCE of $3.2 \%$ of the reference device. The reduction in PCE was due to reduced $V_{\mathrm{oc}}, J_{\mathrm{sc}}$ and $\mathrm{FF}$ and the PCE reduction increased with the Au-DDA NP loading. This negative effect of $\mathrm{Au}-\mathrm{DDA}$ NPs in P3HT:PC ${ }_{61} \mathrm{BM}$ devices is different from the positive effect of Au-DDA NPs in P3OT: $\mathrm{C}_{60}$ devices in [15]. Topp et al. argued that the insulating nature of the DDA ligand shell as evidenced by the forward biased dark $I V$ characteristic is the cause of the negative effect.
Since ligands with long hydrocarbon chains were found to hinder charge transport, the DDA ligands were replaced by pyridine $\left(\mathrm{C}_{5} \mathrm{H}_{5} \mathrm{~N}\right)$ via ligand exchange [27]. The ligand exchange involved dissolving the DDA stabilized Au NPs in pyridine at room temperature. Then, the pyridine-stabilized Au NPs were precipitated by adding hexane slowly to the pyridine. This ligand exchange procedure resulted in Au-pyridine NPs that did not show agglomeration effect and an average diameter of $\sim 15 \mathrm{~nm}$. Au-pyridine NPs dissolved in pyridine were mixed with a chlorobenzene solution containing $\mathrm{P} 3 \mathrm{HT}$ and $\mathrm{PC}_{61} \mathrm{BM}$. The resulting P3HT: $\mathrm{PC}_{61} \mathrm{BM}$ devices containing $23 \mathrm{wt} \%$ Au-pyridine NPs with respect to P3HT had a measured PCE of $1.1 \%$. This was again lower than the reference P3HT:PC ${ }_{61} \mathrm{BM}$ device with a PCE of $2.4 \%$. The quenching of the excited state by the pyridine was suggested by Topp et al. as a possible reason for the negative effect observed.

Wang et al. [30] carried out a combined experimental and computational study of the effect of Au NPs on the BHJ layer of polymer OPV devices. The Au NPs used in this study were synthesized by refluxing a $\mathrm{HAuCl}_{4}$ solution containing $\mathrm{Au}$ together with the reducing agent sodium citrate. After synthesis, the Au NPs were added to an aqueous solution of $O$-[2-(3-mercaptopropionylamino) ethyl]- $O^{\prime}$-methylpolyethylene glycol (monofunctional PEG) to form ligand stabilized Au NPs in a chlorobenzene/ chloroform solvent. The monofunctional PEGs are a member of the polyethylene oxides. Transmission electron microscopy (TEM) observation showed that the Au NPs have an average diameter of $18 \mathrm{~nm}$ and the LSPR absorption peak is located at $\sim 520 \mathrm{~nm}$ [30]. The donor copolymer poly(2,7-(9,9 dioctylfluorene)-alt-2-((4-(diphenylamino) phenyl)thiophen-2-yl)malononitrile)] (PFSDCN) synthesized by a post-functionalized approach has an optical bandgap of $2.05 \mathrm{eV}$ [30]. Monofunctional PEGcapped Au NPs, PFSDCN and $\mathrm{PC}_{61} \mathrm{BM}$ were mixed in the same chlorobenzene/chloroform solvent and spin coated onto PEDOT:PSS/ITO to form the active layer of OPV devices. The wt $\%$ of Au NPs in plasmonic devices expressed a percentage of the PFSDCN weight ranged from 0 to $6 \mathrm{wt} \%$. From the $J-V$ characteristics under illumination, Wang et al. [30] found that $V_{\mathrm{oc}}, J_{\mathrm{sc}}$ and FF initially increased with the Au NP concentration up to $0.5 \mathrm{wt} \%$ and then decreased (Fig. 1). The $V_{\text {oc }}$ decreased from a maximum of $1.0 \mathrm{~V}$ at $0.5 \mathrm{wt} \%$ to only $0.4 \mathrm{~V}$ at $6 \mathrm{wt} \% \mathrm{Au}$ NPs while $J_{\mathrm{sc}}$ decreased from about $4 \mathrm{~mA} / \mathrm{cm}^{2}$ to nearly zero over the same range of NP concentration. FF on the other hand remained above 0.4 until the Au NP concentration reached $4 \mathrm{wt} \%$ and then decreased rapidly. As a result of these trends, the PCE exhibited a maximum of $2.17 \%$ at $0.5 \mathrm{wt} \% \mathrm{Au} \mathrm{NP}$ compared with $1.64 \%$ for the control device. At $6 \mathrm{wt} \%$ Au NPs, the PCE dropped to $0.01 \%$ due to negligible $V_{\mathrm{oc}}$ and $J_{\mathrm{sc}}$. To understand why 

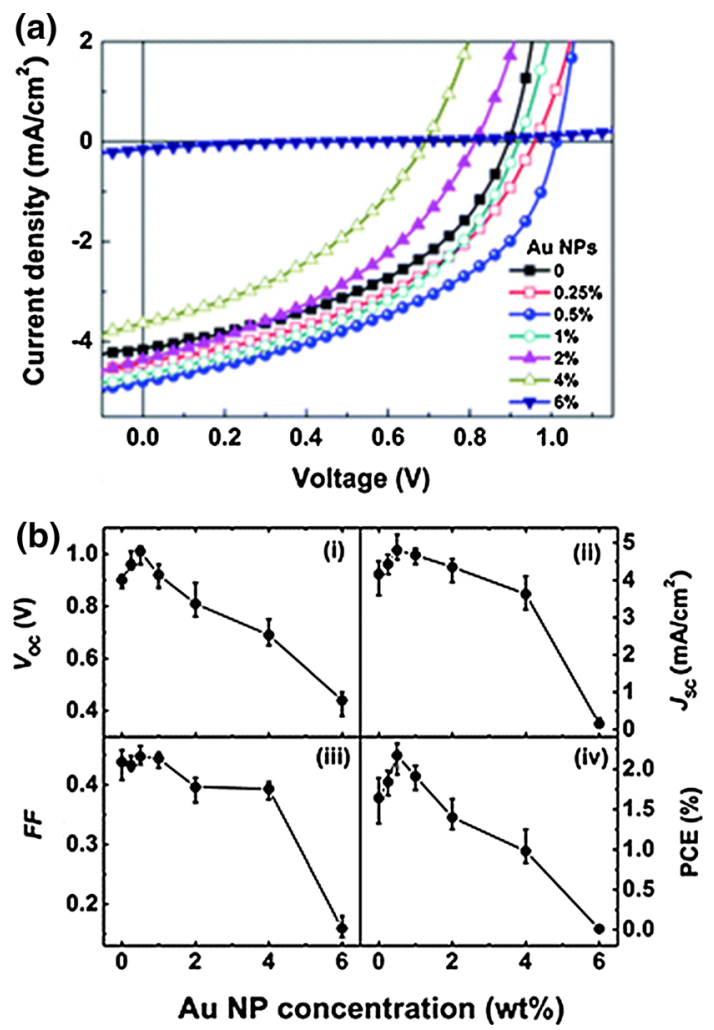

Fig. 1 a $J-V$ characteristics of PFSDCN:PC ${ }_{61} \mathrm{BM}$ OPV devices with different $\mathrm{Au} \mathrm{NP}$ concentration under illumination; $\mathbf{b}$ Variation of $V_{\mathrm{oc}}$, $J_{\mathrm{sc}}, \mathrm{FF}$ and PCE of PFSDCN:PC ${ }_{61} \mathrm{BM}$ device with different $\mathrm{Au}$ NP concentration in the BHJ Reproduced from J. Mater. Chem. 22, 1206-1211 (2012) with permission of The Royal Society of Chemistry [30]

monofunctional PEG-capped Au NPs only had a modest positive effect on $\mathrm{PFSDCN} / \mathrm{PC}_{61} \mathrm{BM}$ devices at low $\mathrm{NP}$ concentrations, dark $J V$ characteristics were measured. The dark current at low forward bias increased with Au NP loading up to $2 \mathrm{wt} \%$ and then decreased. This showed that as in [15], the conductivity of the BHJ was initially improved by the presence of the NPs. Furthermore, at $0.5 \mathrm{wt} \% \mathrm{Au}$ NPs, the effect of the PEG on the conductivity was shown by the $J-V$ characteristics of PEG only devices to be insignificant.

Monofunctional PEG-capped Au NPs were also found to be effective in enhancing the PCE of P3HT:PC ${ }_{61} \mathrm{BM}$ devices. In their study [31], Xie et al. incorporated $35 \mathrm{~nm}$ PEG-capped $\mathrm{Au} \mathrm{NPs}$ into the absorber layer of ITO/PEDOT:PSS/ $\mathrm{P} 3 \mathrm{HT}: \mathrm{PC}_{61} \mathrm{BM} / \mathrm{LiF} / \mathrm{Al}$ devices at a concentration of $1.2 \mathrm{wt} \%$. The measured PCE of this device (3.41\%) was higher than that of the reference device without NPs $(3.16 \%)$ because of improved $J_{\mathrm{sc}}$ and FF. This result is interesting because the PCE enhancement is the opposite of that observed by Topp et al. [27] for the same BHJ and the same Au NPs. Xie et al. however, did not study the effect of increasing Au NP concentration on the PCE of P3HT: $\mathrm{PC}_{61} \mathrm{BM}$ devices.

\section{Ag and AuAg NP}

The experimental observations for Ag NPs in the BHJ are similar to those for Au. While Kim and Carroll [15] found that Ag NPs with organic ligands have a beneficial effect on P3OT/ $/ \mathrm{C}_{60}$ devices, the negative effect of $\mathrm{Ag}$ NPs with organic ligands on other polymer OPV devices had also been widely observed. Xue et al. [32] studied the effect of incorporating Ag NPs functionalized with organic ligands on the charge carrier dynamics in P3HT: $\mathrm{PC}_{61} \mathrm{BM}$ blends. The 5-15 nm Ag NPs used had a ligand shell consisting of dodecanethiol $\left(\mathrm{CH}_{3}\left(\mathrm{CH}_{2}\right)_{11} \mathrm{SH}\right)$ and were added to $\mathrm{P} 3 \mathrm{HT}: \mathrm{PC}_{61} \mathrm{BM}$ at different weight ratios. Carrier mobility in the blends with and without Ag NPs was measured by the photoinduced charge extraction with a linearly increasing voltage (photo-CELIV) technique. In photoCELIV, carriers generated by a short light pulse are extracted by a linearly increasing voltage and the resulting current transient is recorded as a function of the time delay between the light pulse and the start of the ramp [33]. The carrier mobility can be calculated from the parameters of the current transient, the gradient of the ramp and the active layer thickness. From their photo-CELIV measurements, Xue et al. found that the carrier mobility in $\mathrm{P} 3 \mathrm{HT}: \mathrm{PC}_{61} \mathrm{BM}$ blends increased by up to a factor of 10 as the concentration of $\mathrm{Ag}$ NPs is increased from zero for the control device. For high Ag NP concentration, atomic force microscopy (AFM) phase images showed the Ag NPs phase separated into separate domains which provide an alternative conduction pathway with higher mobility (Fig. 2). The higher carrier mobility observed by photoCELIV is, therefore, due to the onset of phase separation by Ag NPs. The phase separation is attributed to incompatibility between the dodecyl side chains of the ligands and the donor and acceptor molecules [32].

The PCE of P3HT: $\mathrm{PC}_{61} \mathrm{BM}$ devices measured under air mass AM 1.5G (global) illumination decreased from 3.4\% for the control device to $\sim 2 \%$ for the highest $\mathrm{Ag} \mathrm{NP}$ concentration [32]. The cause of this reduction was studied by integrating the photo-CELIV current transient for different time delays. This integral which is the total extracted charge density decreases as a power law with the time delay for all devices. However, the rate of decrease is greater at higher Ag NP concentration. This suggests that there is increased carrier recombination at the surface of the Ag NPs and the PCE decrease is, therefore, due to reduced charge extraction despite increased carrier mobility.

In another study [34], Yoon et al. investigated the effect of self-assembled $\mathrm{Ag}$ NPs on the performance of P3HT:PC ${ }_{61} \mathrm{BM}$ devices. The Ag NPs synthesized by thermal decomposition of an organic Ag salt in toluene had a carboxylic ligand shell with an average particle diameter of 
P3HT:PCBM only
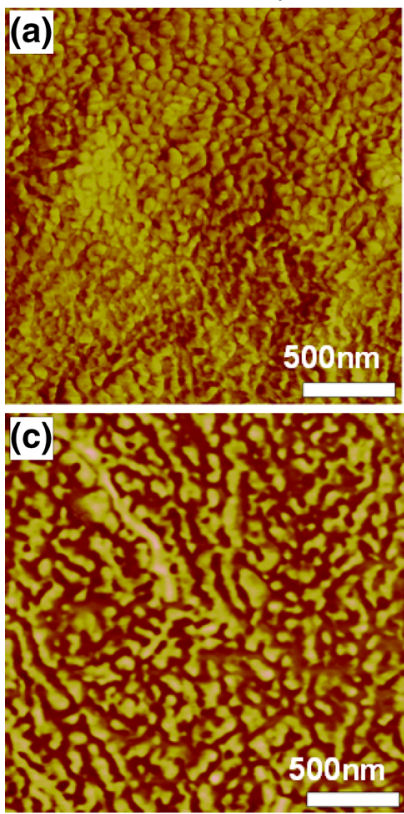

8:1 P3HT:AgNP
16:1 P3HT:AgNP
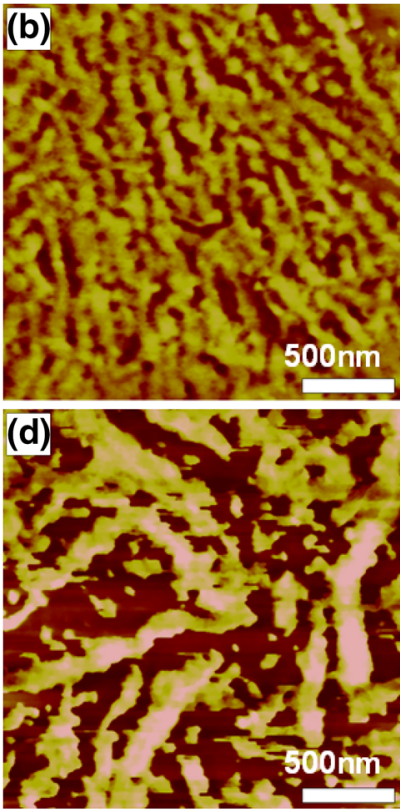

4:1 P3HT:AgNP
Fig. 2 AFM phase images of: a P3HT:PC ${ }_{61} \mathrm{BM}$ BHJ; b P3HT:PC 61 $\mathrm{BM}$ with a 16:1 mass ratio of P3HT:Ag NP; $\mathbf{c}$ P3HT:PC ${ }_{61} \mathrm{BM}$ with a 8:1 mass ratio of P3HT:Ag NP and $\mathbf{d}$ P3HT: $\mathrm{PC}_{61} \mathrm{BM}$ with a $4: 1$ mass ratio of P3HT:Ag NP. Phase separation in $\mathbf{d}$ results in formation of alternative conduction pathways. Reprinted from Appl. Phys. Lett. 98, 253302 (2011) with the permission of AIP Publishing [32]

$3.65 \mathrm{~nm}$ and a narrow particle size distribution. When these Ag NPs were spin coated onto PEDOT:PSS/ITO substrates, they self-assembled into ordered arrays of $\sim 4 \mathrm{~nm}$ NPs with an LSPR peak at $465 \mathrm{~nm}$. When a layer of $\mathrm{P} 3 \mathrm{HT}: \mathrm{PC}_{61} \mathrm{BM}$ (1:1 weight ratio) was spin coated onto the self-assembled Ag NPs, the total optical absorption over the spectral range of $350-650 \mathrm{~nm}$ was found to be enhanced by $\sim 16 \%$ due to the LSPR [34].

OPV devices with the structures of ITO/PEDOT:PSS/ Ag NP/P3HT:PC ${ }_{61} \mathrm{BM} / \mathrm{Ca} / \mathrm{Al}$ and ITO/PEDOT:PSS/ $\mathrm{P} 3 \mathrm{HT}: \mathrm{PC}_{61} \mathrm{BM} / \mathrm{Ca} / \mathrm{Al}$ were fabricated by spin coating and thermal evaporation. The dark $J-V$ characteristic of the plasmonic device with Ag NPs between the P3HT: $\mathrm{PC}_{61} \mathrm{BM}$ active layer and the PEDOT:PSS layer had a much lower rectification ratio at $\pm 1 \mathrm{~V}$ than the control device (Fig. 3a) [34]. (The rectification ratio is defined as the ratio of the dark current at +1 and $-1 \mathrm{~V}$.) This low rectification ratio of the plasmonic device was due to a much higher reverse leakage current caused by greater surface recombination at the Ag NPs.

Under illumination by calibrated $\mathrm{AM} 1.5 \mathrm{G}$ simulated solar irradiance at $100 \mathrm{~mW} / \mathrm{cm}^{2}$, the P3HT: $\mathrm{PC}_{61} \mathrm{BM}$ device with the self-assembled Ag NP layer exhibited a higher $J_{\mathrm{sc}}$ than the control device (Fig. 3b). This enhancement was explained using the LSPR of the Ag NPs on the exciton generation in the active layer. However, the $V_{\mathrm{oc}}$ and FF of
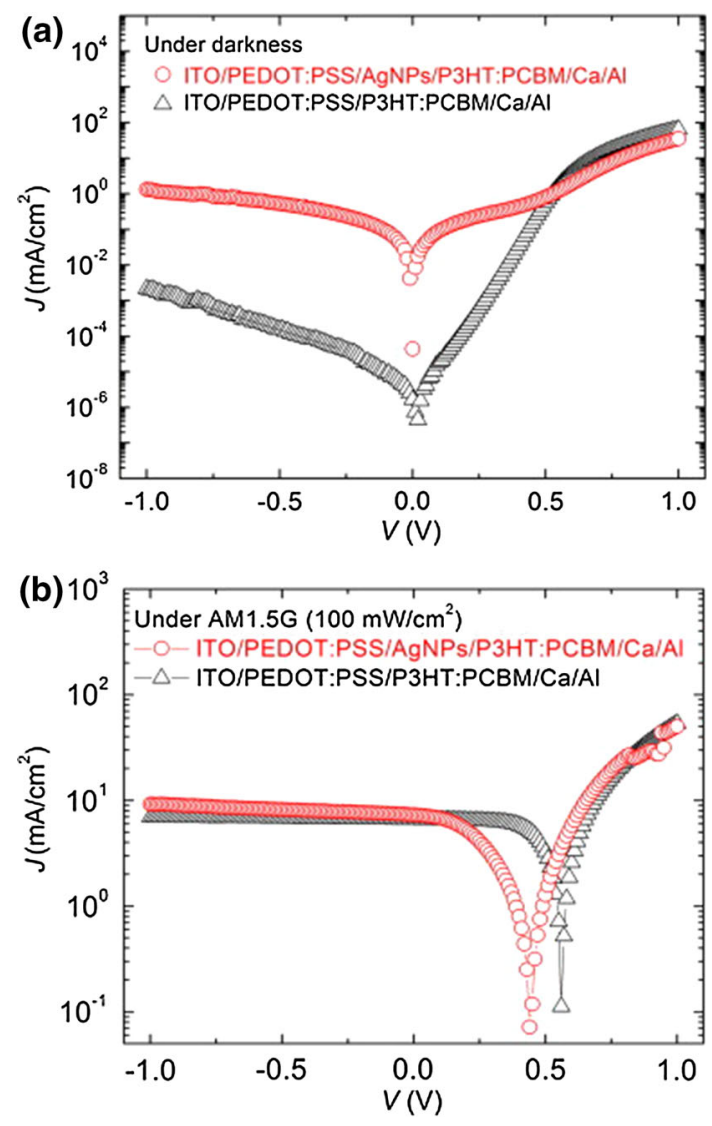

Fig. 3 a Dark $J-V$ characteristics of ITO/PEDOT:PSS/AgNP/ $\mathrm{P} 3 \mathrm{HT}: \mathrm{PC}_{61} \mathrm{BM} / \mathrm{Ca} / \mathrm{Al}$ device and reference; $\mathbf{b} J-V$ characteristics of ITO/PEDOT:PSS/AgNP/P3HT:PC ${ }_{61} \mathrm{BM} / \mathrm{Ca} / \mathrm{Al}$ device and reference under AM 1.5G illumination. Reprinted form Solar Energy Materials and Solar Cells, 94, Woo-Jun Yoon, Kyung-Young Jung, Jiwen Liu, Thirumalai Duraisamy, Rao Revur, Fernando L. Teixeira, Suvankar Sengupta, Paul R. Burger, Plasmon-enhanced optical absorption and photocurrent in organic bulk heterojunction photovoltaic devices using self-assembled layer of silver nanoparticles, 128-132 (2010), with permission from Elsevier [34]

the plasmonic device were both lower than the control device. The lower $V_{\text {oc }}$ was attributed to an increased carrier recombination at the interface of the self-assembled Ag NP layer and the active layer while the lower FF was explained in terms of an increased specific series resistance and reduced shunt resistance [34]. As a result, the average PCE of the plasmonic device $(1.2 \%)$ is lower than the control (2.2\%) despite the improved $J_{\text {sc }}$. When the self-assembled Ag NP layer was placed between the ITO and the PEDOT:PSS layers, the $V_{\mathrm{oc}}$ was unchanged relative to the control device. However, the FF was still lower than the control and there was no enhancement in $J_{\mathrm{sc}}$. These results show clearly that small diameter Ag NPs with carboxylic ligands are not suitable NPs for enhancing the photovoltaic performance of $\mathrm{P} 3 \mathrm{HT}: \mathrm{PC}_{61} \mathrm{BM}$ devices.

In a related study, Pei et al. [35] studied the effect of $\mathrm{Ag}$ ND self-assembled on ITO on the performance of 
P3HT:PC ${ }_{61}$ BM OPV devices. Ag NDs with an average diameter of $46.7 \mathrm{~nm}$ were synthesized by the photo-induced seed growth method [36]. In this method, Ag nuclei were formed by reducing an aqueous solution of $\mathrm{AgNO}_{3}$ using $\mathrm{NaBH}_{4}$. The NDs were capped by negatively charged trisodium citrate and the Ag ND solution had an LSPR peak at $540 \mathrm{~nm}$. The negative charge of the ligand molecules enabled electrostatic self-assembly to occur when a positively charged ITO substrate was immersed into a colloidal solution of the Ag NDs. For an immersion time of $30 \mathrm{~min}$, the average PCE of ITO/AgND/PEDOT:PSS/ P3HT:PCBM/LiF/Al device was 3.45 versus $2.72 \%$ for the control because of improvements in $J_{\mathrm{sc}}$ and FF. The enhancement mechanism was attributed to increased light scattering into the active layer and the localized fields around the ND facilitating absorption in the active layer. This study demonstrates the advantage of using larger plasmonic nanostructures in OPV devices. However, it should be noted that the ND is not incorporated into the BHJ in this study.

The use of metal alloy NPs in plasmonic OPV devices has also been reported by Chen et al. [37]. Unlike metallic NPs, the characteristic LSPR peak of alloy NPs is tunable through the composition of the alloy. In this study, larger diameter $\mathrm{Au}_{11} \mathrm{Ag}_{89}$ and $\mathrm{Au}_{28} \mathrm{Ag}_{72}$ alloy NPs were synthesized by a one-pot reaction. The precursors for $\mathrm{Au}$ and $\mathrm{Ag}$ were gold acetate $\mathrm{Au}(\mathrm{ac})_{3}$ and $\mathrm{AgNO}_{3}$, respectively. These precursors were mixed in proportion to the composition of the alloy NP with several stabilizing ligands, namely trioctylphosphine (TOP), 1,2-dodecanediol (DOD), oleylamine (OAm) and oleic acid (OAc) in octyl ether [37]. The mixture was then heated and refluxed to form the alloy NPs. The TOP is especially critical as it forms a metal ligand complex with $\mathrm{Ag}$ that reduces the nucleation rate so that larger diameter $(\sim 20 \mathrm{~nm})$ alloy NPs can be grown from the precursors in the reaction mixture. Since multiple organic ligands were used in the synthesis, energy dispersive spectroscopy (EDS) analysis of the $\mathrm{Au}_{11} \mathrm{Ag}_{89}$ NPs consisted of $\mathrm{Au}, \mathrm{Ag}$ and a third $\mathrm{C}$ peak [37]. (The $\mathrm{C}$ peak for the $\mathrm{Au}_{28} \mathrm{Ag}_{72}$ NPs is weaker [37]). The LSPR peak wavelengths of the $\mathrm{Au}_{11} \mathrm{Ag}_{89}$ and $\mathrm{Au}_{28} \mathrm{Ag}_{72}$ NPs are between those of $\mathrm{Au}$ and $\mathrm{Ag}$ NPs.

When $\mathrm{Au}_{11} \mathrm{Ag}_{89}$ NPs were incorporated into ITO/ PEDOT:PSS/P3HT:PC ${ }_{61} \mathrm{BM} / \mathrm{Ca} / \mathrm{Al}$ devices at $1 \mathrm{wt} \%$ of the active layer, a PCE of $4.73 \%$ was obtained which was higher than that of the reference device at $3.61 \%$. For $\mathrm{Au}_{11} \mathrm{Ag}_{89}$ weight percentage above $1 \mathrm{wt} \%$, the PCE of devices incorporated with these NPs decreased because the insulating ligands of the NPs hinder the charge transport within the active layer [37]. In addition, from EDS characterization, the ligands can result in increased charge trapping and recombination in this layer [37]. Likewise, incorporation of $\mathrm{Au}_{28} \mathrm{Ag}_{72}$ NPs into the active layer of
ITO/PEDOT:PSS/P3HT:PC ${ }_{61} \mathrm{BM} / \mathrm{Ca} / \mathrm{Al}$ device at any wt\% resulted in a $\mathrm{PCE}$ that was lower than the reference device at $3.61 \%$ [37]. This is because the $\mathrm{Au}_{28} \mathrm{Ag}_{72} \mathrm{NPs}$ tend to aggregate within the $\mathrm{BHJ}$ and the resulting morphology of the BHJ became unfavorable for charge separation and transport.

\section{Effect of organic ligands in BHJ devices}

Organic ligand molecules play crucial roles in the solution synthesis of colloidal NPs and nanocrystals. They are added to mediate the solution reaction between the precursor materials of the NP being synthesized. The effects of organic ligands on NP synthesis can include: nucleation rate from the supersaturated solution, prevention of excessive growth of nuclei and agglomeration, stabilization of the colloidal NP, passivation of NP surface states, morphology control of anisotropic NPs and the final NP size distribution [38]. Some of the organic ligands commonly used for NP synthesis are: tri- $n$-octylphosphine oxide (TOPO), TOP, long-chain aliphatic amines, thiols and carboxylic acids [38]. These ligands consist of an anchoring group that bind to the NP surface and an alky chain. In some synthesis (e.g., Ref. [37]), multiple ligands are utilized to achieve a higher degree of control over particle characteristics. The ligands used during synthesis can be exchanged with another ligand after synthesis by dispersing the NP into a solution containing the new ligand. Ligand exchange can be used to improve the electrical properties of NP films [38]. Since NPs have very large surface area to volume ratios, the organic ligands attached to the NP surface (or surface chemistry) will undoubtedly have a major impact on the electronic and optical properties of colloidal NPs. Furthermore, if the ligands interfere with any of the elementary processes in energy harvesting when incorporated into the $\mathrm{BHJ}$, they should result in a negative impact on the device PCE.

By studying the extensive literature on II-VI semiconductor nanocrystals used in quantum dot polymer BHJ PV devices, one can gain insight into the effects that colloidal metallic NPs may exert on the BHJ layer of plasmonic OPV devices [39]. It is known that the surface ligands can affect the photoluminescence (PL) quantum efficiency, charge transport efficiency and the length scale of the phase separation. In some systems, even the electronic energy levels of the quantum dot and the energetics of the device can be tuned [39]. For CdSe nanocrystals, some ligands can enhance the radiative recombination via defect sites and give rise to a broader PL emission peak in addition to the band edge emission peak [40]. On the other hand, some ligands can quench the band edge emission from electronic states associated with the nanocrystal core [40]. Since 
(a)

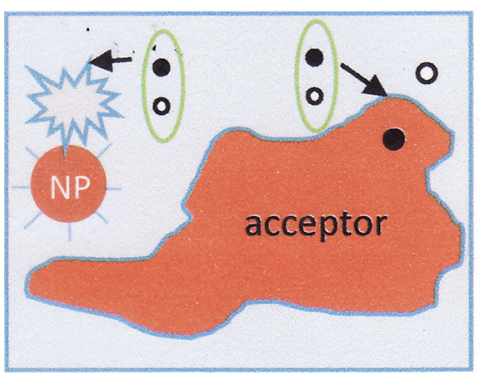

Exciton quenching (b)

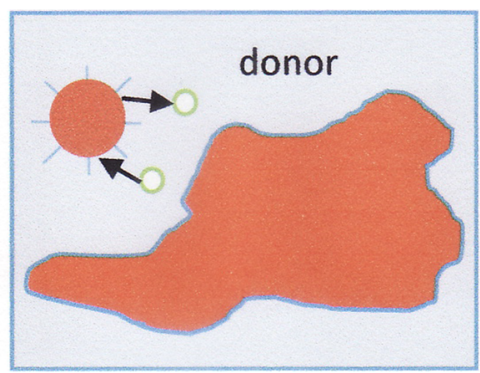

NP charging (c)

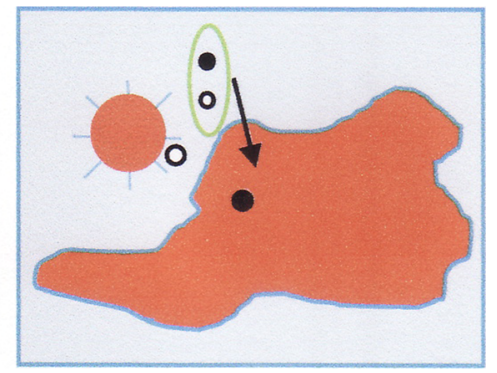

Charge trapping

Fig. 4 a Exciton quenching by ligands on the surface of metallic NP; $\mathbf{b}$ charging of metallic NP by dissociated charge carriers and c carrier trapping by metallic NP

excitons can be generated near metallic NPs with organic ligands, a similar quenching process can take place in OPV devices with NP embedded in the BHJ (Fig. 4a).

Colloidal semiconductor NPs are also prone to charging which is the generally accepted cause of the blinking phenomenon [41]. In this process, a charge carrier tunnels either into or from the NP and causes the NP core to acquire a net charge (Fig. 4b). The charged core can enable Auger recombination and reduce emission in quantum dot light emitting devices. It is conceivable that similar processes can occur after exciton dissociation in colloidal metallic NP incorporated into a BHJ. However, further research is needed to verify this conjecture. A third process that may occur is charge trapping and is illustrated in Fig. 4c.

\section{Bare noble metal NP in BHJ}

\section{Au NP}

Since chemically synthesized Au or Ag NPs with organic ligands tend to have a negative impact when incorporated into the BHJ layer of OPV devices, ligand-free NP synthesis methods have been studied by various groups [16]. In 2012, Spyropoulos et al. [42] observed a positive effect of surfactant-free Au NPs in P3HT:PC ${ }_{61}$ BM devices. The surfactantfree $\mathrm{Au}$ NPs used in this study were prepared by a pulsed laser ablation method [34]. An Au target immersed in a cell with absolute ethanol was ablated by focusing a $0.1 \mathrm{ps}$, $1 \mathrm{kHz}$ pulsed laser onto the Au surface [43]. During ablation, the sample cell was scanned relative to the laser beam. Surfactant-free Au NP with a broad size distribution from 1.5 to $40 \mathrm{~nm}$ was obtained (Fig. 5). These Au NPs when dissolved in ethanol have an LSPR absorption peak at $530 \mathrm{~nm}$ (Fig. 5). By blending these surfactant-free Au NPs into the active layer of ITO/PEDOT:PSS/P3HT:PC ${ }_{61} \mathrm{BM} / \mathrm{Al}$ devices at $3-6$ vol\% of the P3HT:PC ${ }_{61} \mathrm{BM}$ solution, plasmonic devices with various Au NP concentrations were fabricated.

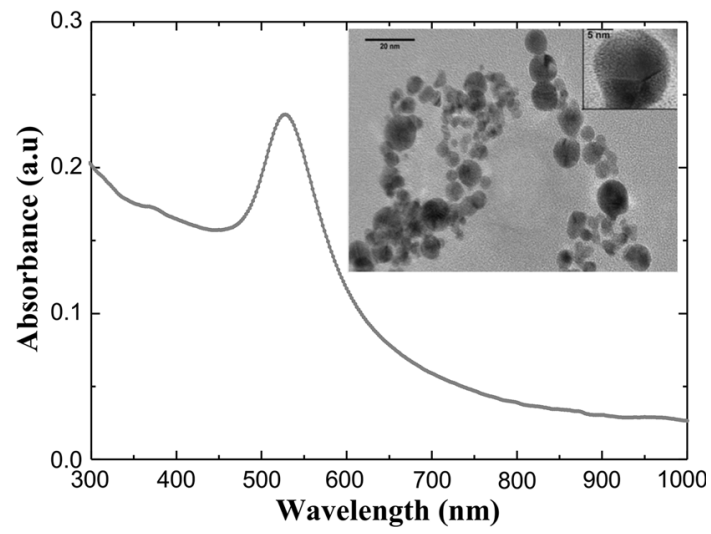

Fig. 5 Absorbance spectrum and TEM image of surfactant-free $\mathrm{Au}$ NPs synthesized by pulsed laser ablation. The LSPR absorbance peak is at $520 \mathrm{~nm}$. Reprinted from Appl. Phys. Lett. 100, 213904 (2012) with the permission of AIP Publishing [42]

The average PCE of the optimized devices with 5\% Au NPs in the $\mathrm{BHJ}(3.71 \%)$ is substantially higher than the average PCE of the control (2.64\%) [43]. The improvement was due to an increase in both $J_{\mathrm{sc}}$ and FF but there was no change in $V_{\mathrm{oc}}$. The enhanced localized fields around the smaller $\mathrm{Au}$ NPs and increased light scattering by the larger Au NPs were used to explain the increased photocurrent generation. One other notable observation by Spyropoulos et al. is that the incorporation of surfactant-free Au NPs also improved the morphological stability of the BHJ blend. This results in an improved photodegradation stability in these devices compared with devices without surfactant-free Au NPs [44].

An improved PCE was also observed when bare Au NPs were introduced into the active layer of a low bandgap polymer:fullerene OPV device. A low bandgap polymer is generally defined as a semiconducting polymer with a HOMO-LUMO gap below $2 \mathrm{eV}$ [8, 45]. In their study [46], Wang et al. studied the blends of poly $\left[\mathrm{N}-9^{\prime \prime}\right.$-hepta-decanyl2-7-carbazole-alt-5,5-(4'-7'-di-2-thienyl-2', $1^{\prime}, 3^{\prime}$-benzothiadiazole)] (PCDTBT) with [6]-phenyl $\mathrm{C}_{70}$ butyric acid methyl ester $\left(\mathrm{PC}_{71} \mathrm{BM}\right)$ and poly([4,4'-bis(2-ethylhexyl) dithieno(3,2-b:2',3'-d) silole]-2,6-diyl-alt-[4,7 bis(thienyl)- 


\section{2,1,3-benzothiadiazole]-5,5'-diyl) (Si-PCPDTBT):PC 71 -} $\mathrm{BM}$ blends. The NPs blended into these two BHJ layers were chemically synthesized truncated octahedral Au NPs. The synthesis involved dissociation of tetrachloroaurate trihydrate $\left(\mathrm{HAuCl}_{4}: 3 \mathrm{H}_{2} \mathrm{O}\right)$ by deionized water followed by chemical reduction by $\mathrm{N}, \mathrm{N}$ dimethylformamide (DMF). To yield truncated octahedral NPs, an organic capping agent poly(vinylpyrrolidone) (PVP) was added to suppress the growth of certain facets of the growing Au NPs. Significantly, the PVP capping agent was first removed by centrifugation from the precipitated Au NPs before they were introduced into the BHJ layer. Wang et al. used EDS to confirm that the truncated octahedral Au NPs consisted of pure Au and scanning electron microscopy (SEM) showed that they had a diameter of about $70 \mathrm{~nm}$. When these truncated octahedral $\mathrm{Au}$ NPs were introduced into the PCDTBT:PC ${ }_{71} \mathrm{BM}$ BHJ at $5 \mathrm{wt} \%$, the resulting ITO/PEDOT:PSS/PCPDTBT:PC ${ }_{71} \mathrm{BM} / \mathrm{TiO}_{x} / \mathrm{Al}$ devices had a measured PCE of $6.45 \%$ [46]. For the reference device for this BHJ without Au NPs, the PCE was 6.11\% [46]. When truncated octahedral $\mathrm{Au}$ NPs were introduced to the $\mathrm{Si}-$ PCPDTBT:PC ${ }_{71} \mathrm{BM}$ BHJ, the PCE of ITO/PEDOT:PSS/SiPCPDTBT:PC ${ }_{71} \mathrm{BM} / \mathrm{TiO}_{x} / \mathrm{Al}$ devices was $4.54 \%$ compared with $4.28 \%$ for the reference device [46]. Since the thickness of the active layer of the devices with Au NPs and the respective reference devices were not the same, devices with different active layer thickness were fabricated and measured to confirm that the Au NPs were indeed causing the efficiency enhancement. For the enhancement mechanism, Wang et al. measured the diffuse reflectance spectra of P3HT: $\mathrm{PC}_{71} \mathrm{BM}$ devices with and without truncated octahedral Au NPs. When Au NPs were present in the BHJ, the diffuse reflectance was reduced across the entire spectral region measured. This shows that the embedded Au NPs increased light absorption in the active layer as a result of increased light scattering by these larger NPs.

Wang et al. reported an interesting effect of ligand-free Au octahedral NP for the P3HT: $\mathrm{PC}_{70} \mathrm{BM}$ system. As with the two low band gap polymers, the incorporation of surfactantfree truncated octahedral Au NPs into the BHJ led to an increase in the PCE of P3HT:PC ${ }_{71} \mathrm{BM}$ OPV devices. However, for the optimized P3HT: $\mathrm{PC}_{71} \mathrm{BM}$ device with $5 \mathrm{wt} \%$ of the NPs, the improvement was due to both an increase in $V_{\mathrm{oc}}$ and $J_{\mathrm{sc}}$. This is not the case for the PCDTBT and $\mathrm{Si}-$ PCPDTBT. The origin of the $V_{\mathrm{oc}}$ increase was studied by ultraviolet photoelectron spectroscopy (UPS) [46]. It was found that in the case of P3HT:PC ${ }_{71} \mathrm{BM}$ with Au NPs, the energy barrier for hole extraction with respect to the Fermi energy for ITO was reduced relative to $\mathrm{P} 3 \mathrm{HT}: \mathrm{PC}_{71} \mathrm{BM}$ due to a shift in the vacuum energy level (Fig. 6). Since this facilitates carrier extraction, carrier recombination should be reduced and this causes $V_{\mathrm{oc}}$ to increase.

\section{Ag NP}

An electron beam evaporation (EBE) method was used by Kalfagiannatis et al. to deposit Ag NPs onto the surface of a polymer BHJ in an ultra-high vacuum [47]. In this purely physical method, an electron beam was directed at an $\mathrm{Ag}$ pellet source to evaporate $\mathrm{Ag}$. Ag NPs were formed upon Ag deposition onto the BHJ surface of a ITO/PEDOT:PSS/ $\mathrm{P} 3 \mathrm{HT}: \mathrm{PC}_{61} \mathrm{BM} / \mathrm{Ca} / \mathrm{Al}$ device structure and thermal annealing at $145{ }^{\circ} \mathrm{C}$ [47]. AFM analysis of the BHJ surface showed that the Ag NPs has a bimodal size distribution with one peak at $\sim 12 \mathrm{~nm}$ and another peak at $\sim 23 \mathrm{~nm}$ [47]. The surface morphology of the BHJ was not altered by the deposition of $\mathrm{Ag}$ and annealing. The PCE of the device with Ag NPs on the active layer (2.65\%) is slightly higher than the reference device $(2.41 \%)$. This increase in PCE was solely due to $J_{\mathrm{sc}}$ because in fact both $V_{\mathrm{oc}}$ and FF decreased slightly. The fact that the shunt resistance $R_{\mathrm{sh}}$ became smaller than the reference device implies more carrier recombination. In addition, the series resistance $R_{\mathrm{S}}$ measured under illumination is about $50 \%$ smaller than that of $R_{\mathrm{s}}$ measured in the dark [47]. Since plasmonic effects cannot take place in the dark, this suggests that the LSPR effect of the Ag NPs incorporated at the top of the BHJ has a net positive influence on device performance.

In another study [48], Wang et al. synthesized Ag NPs from $\mathrm{AgNO}_{3}$ by using PVP as surfactant and a polyol in deionized water. The polyol process typically uses a high boiling point diol as a reducing agent to reduce the metal precursor(s) to form metallic or alloy NP [49]. In this case, the two-stage aqueous reaction involves the oxidation of the polyol to an aldehyde and water followed by the reduction of $\mathrm{AgNO}_{3}$ to $\mathrm{Ag}$ by the aldehyde. By varying the polyol used, the size of the Ag NPs can be controlled to between 30 and $60 \mathrm{~nm}$ (Fig. 7). EDS analysis showed that the Ag NPs consisted mainly of elemental Ag but peaks corresponding to $\mathrm{Si}$ and $\mathrm{C}$ are also present [39]. When $40 \mathrm{~nm}$ Ag NPs in ethanol with an LSPR absorbance peak at $420 \mathrm{~nm}$ were introduced into a PCDTBT:PC ${ }_{71} \mathrm{BM}$ blend at an optimized concentration of $1 \mathrm{wt} \%$ [48], the PCE of the plasmonic device $(7.1 \%)$ was higher than that of the reference device (6.3\%). Incorporation of 30 and $60 \mathrm{~nm} \mathrm{Ag}$ NPs was also found to be beneficial. From SEM and AFM measurements, the enhancement mechanism was deduced to be the clustering of the Ag NPs into larger groups. These Ag NP clusters act as effective scattering centers and increased the optical path length of sunlight, thus increasing the absorption and EQE for shorter wavelengths. The observation of Ag NP clustering together with the EDS spectrum strongly suggests that the Ag NPs used in this experiment had few remaining organic ligands. This inference is reasonable because one of the main reasons for 
Fig. 6 a Energy diagram of P3HT:PC ${ }_{71} \mathrm{BM}$ BHJ device with $10 \mathrm{~nm}$ Au NP; b energy diagram of $\mathrm{P} 3 \mathrm{HT}: \mathrm{PC}_{71} \mathrm{BM} \mathrm{BHJ}$ device with $70 \mathrm{~nm} \mathrm{Au} \mathrm{NP}$; c UPS spectra of P3HT:PC ${ }_{71} \mathrm{BM}$ device with $70 \mathrm{~nm} \mathrm{Au} \mathrm{NP}$ and reference and d mechanism of efficiency enhancement by the reduced energy barrier for hole extraction when Au NPs are present in $\mathrm{P} 3 \mathrm{HT}: \mathrm{PC}_{71} \mathrm{BM} \mathrm{BHJ}$ device. Reprinted with permission from D.H. Wang, D.Y. Kim, K.W. Choi, J.H. Seo, S,H, Im, J.H. Park, O.O. Park, and A. Heeger, Angewandte Chemie International Edition, Wiley-VCH (c) 2011 WileyVCH Verlag GmbH \& Co. KGaA, Weinheim [46]
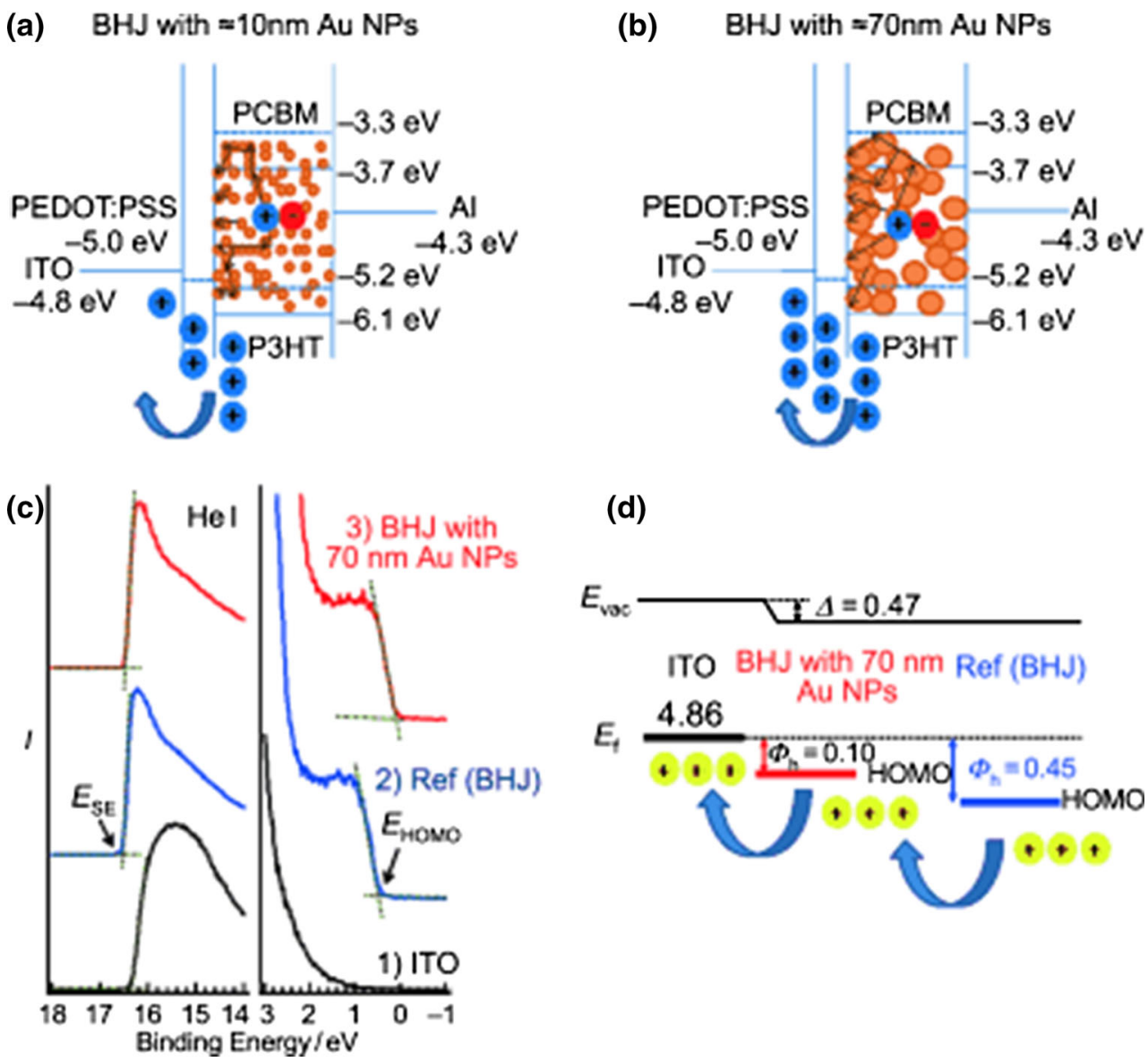

(d)

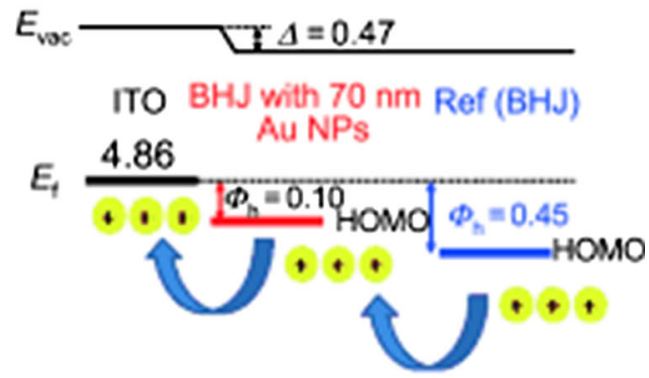

using ligands in NP synthesis is to prevent NP aggregation to reduce surface energy.

Interestingly, in the study by Chen et al. [37] discussed earlier, clustering was also observed for $\mathrm{Au}_{28} \mathrm{Ag}_{72} \mathrm{NPs}$. The EDS spectrum of these NPs has a much reduced $\mathrm{C}$ peak compared with $\mathrm{Au}_{11} \mathrm{Ag}_{79}$ because only $\mathrm{Ag}$ atoms can form a complex with TOP. Incorporation of these $\mathrm{Au}_{28}$ $\mathrm{Ag}_{72}$ NPs into the active layer of ITO/PEDOT:PSS/ $\mathrm{P} 3 \mathrm{HT}: \mathrm{PC}_{61} \mathrm{BM} / \mathrm{Ca} / \mathrm{Al}$ device at any concentration resulted in a PCE that was lower than the reference device $(3.61 \%)$ [37]. This is because the $\mathrm{Au}_{28} \mathrm{Ag}_{72}$ NPs tend to aggregate within the BHJ. The disruption of the BHJ morphology rendered it unfavorable for charge separation and transport.

\section{Core-shell noble metal NP in BHJ}

\section{Au-silica NP}

Another approach to overcome the limitation of metallic NPs with organic ligands in OPV devices is to embed coreshell metal NPs in the BHJ [50, 51]. The core-shell metallic NPs are also chemically synthesized. However, they consist of a metallic core that is encapsulated by an inorganic dielectric outer shell. Thus far, most studies have utilized silica $\left(\mathrm{SiO}_{2}\right)$ as the shell material but other dielectrics can be used. The rationale for having a silica shell around the metallic core is to prevent the recombination and quenching processes that can occur with regard to organic ligands. However, as will be discussed below, there is a tradeoff with the LSPR effect for this approach.

Spherical Au-silica core shell NPs were synthesized by Huang et al. [25] using a two-step process. Au NPs were first prepared by the chemical reduction of $\mathrm{HAuCl}_{4}$ using sodium citrate as reducing agent [25]. After stabilization by PVP molecules, the Au NPs with a typical diameter of $14 \mathrm{~nm}$ were added to a mixture of ammonia and ethanol. In the second stage, the silica precursor tetraethyl orthosilicate (TEOS) was added dropwise to the mixture and a silica shell $\sim 13 \mathrm{~nm}$ thick was formed by an improved Stober process [25]. These Au-silica NPs have one LSPR absorption peak at $528 \mathrm{~nm}$ which is red shifted with respect to that of $\mathrm{Au}$ NPs because of the silica shell [25]. For the investigation of plasmonic effects, an inverted cell structure consisting of ITO/ZnO/P3HT: $\mathrm{PC}_{61} \mathrm{BM} / \mathrm{Ag}$ was used. In the inverted OPV device structure, holes are extracted from the top electrode. The $\mathrm{ZnO}$ layer has a nanowire like morphology to increase the contact area with the BHJ

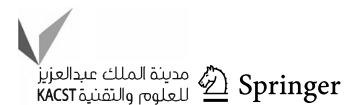


Fig. 7 Schematic diagram of PCDTBT:PC ${ }_{71} \mathrm{BM}$ device enhanced by Ag NP in BHJ. The size of Ag NP synthesized by the polyol method is from 30 to $60 \mathrm{~nm}$. Reprinted with permission from D.H. Wang, K.H. Park, J.H. Seo, J. Seifter, J.H. Jeon, J.K. Kim, J.H. Park, O.O. Park, and A. Heeger, Advanced Energy Materials, Wiley-VCH (c) 2011 Wiley$\mathrm{VCH}$ Verlag $\mathrm{GmbH} \& \mathrm{Co}$. KGaA, Weinheim [48]

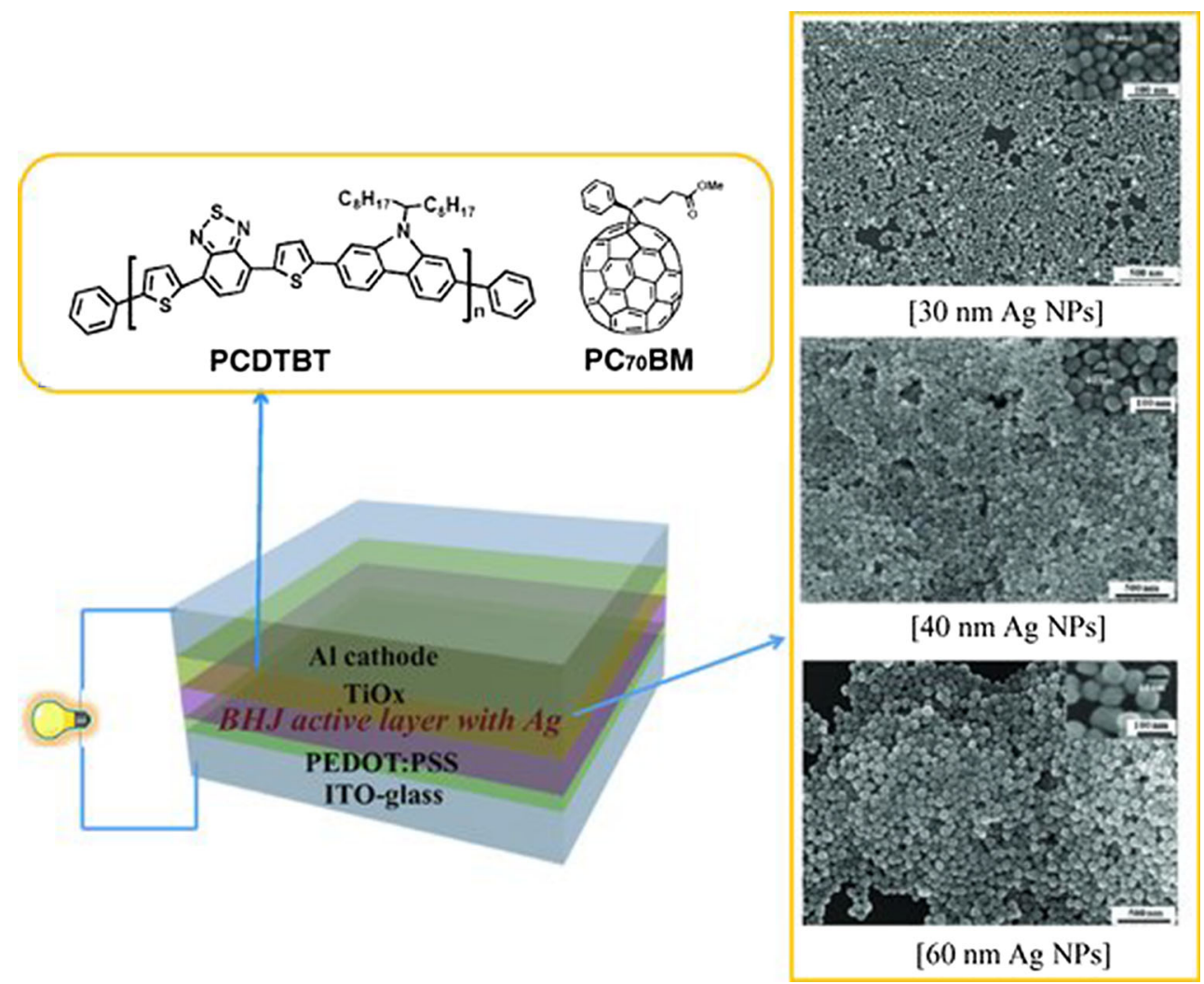

layer. Au-silica NPs were introduced to the BHJ layer at an optimized concentration of $3 \mathrm{wt} \%$ with respect to P3HT. When measured under standard test conditions, the PCE of this inverted plasmonic OPV device was $2.17 \%$ [25]. By comparison, the reference device had a PCE of $1.95 \%$. The PCE of the plasmonic inverted device was improved mainly because of a $27 \%$ enhancement in $J_{\mathrm{sc}}$. In an additional experiment, Huang et al. embedded Au NPs (no shell) into the $\mathrm{BHJ}$ of the inverted device and found that the PCE of this device $(2.44 \%)$ was even higher than the device with Au-silica NPs. This is due to a higher $V_{\mathrm{oc}}$ and FF for the device with Au NPs in the BHJ. Two useful observations can be inferred from this study. First, the incorporation of Au-silica NPs can only have a positive effect with respect to photocurrent generation. Due to the insulating nature of the silica shell, the FF can decrease with the introduction of Au-silica to the BHJ. Second, the incorporation of Au NPs can enhance both $J_{\mathrm{sc}}$ and $V_{\mathrm{oc}}$ for the P3HT: $\mathrm{PC}_{61} \mathrm{BM}$ system. (Note that this is consistent with the finding by Wang et al. [46]). However, due to ohmic losses in metal, the gain in $J_{\mathrm{sc}}$ may be smaller than in the case of Au-silica NPs.

The plasmonic effect of Au-silica NPs can be further enhanced using NP of non-spherical shape with an aspect ratio greater than 1 [51]. An initial demonstration of this was made by $\mathrm{Xu}$ et al. [52]. In this study, Au-silica nanorods (NR) were incorporated into the BHJ of
P3HT:PC ${ }_{71} \mathrm{BM}$ and PCPDTBT:PC ${ }_{71} \mathrm{BM}$ devices. Unlike the spherical NP, an NR has both a longitudinal and a transverse axis for electron oscillation. As a result, the Gan theory shows that there are two LSPR peaks [53]. For Au NRs, both peaks lie within the visible region of the spectrum and thus can result in greater absorption enhancement. In Ref. [52], Au NRs were first synthesized by a two-step seed mediated method. In the first step, Au seed NPs were synthesized by reduction of $\mathrm{HAuCl}_{4}$ using $\mathrm{NaBH}_{4}$ in the presence of hexadecyltrimethylammonium bromide $(\mathrm{CTAB}) . \mathrm{CTAB}$ is an organic ligand that can influence the growth rate of certain crystallographic planes of the Au NP and thus give rise to anisotropic growth. Subsequently, the $\mathrm{Au}$ seed NPs were added to an aqueous solution of $\mathrm{HAuCl}_{4}$ containing CTAB and several other reagents for NR growth [52]. After NR formation, the silica shell was synthesized using TEOS in alkaline conditions. These as-synthesized core-shell NRs are hydrophilic and as such are difficult to be dispersed in an organic solvent. As a result, hexadecyltrimethoxysilane was used to functionalize the surface of the silica before dispersion in an organic solvent.

The diameter and core length of the Au-silica NRs are 34.3 and $92.5 \mathrm{~nm}$, respectively (Fig. 8) [52]. These are larger than those used in the study by Huang et al. [25]. In addition, the silica shell $(17 \mathrm{~nm})$ is also relatively thick (see later). The transverse and longitudinal LSPR extinction peaks located at 530 and $720 \mathrm{~nm}$, respectively, are 


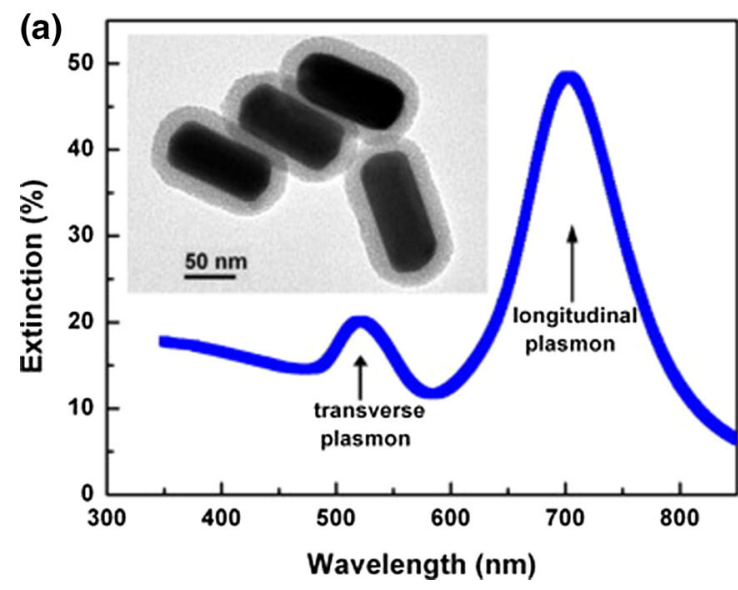

Fig. 8 a TEM image of Au-silica NRs synthesized by the seedmediation method with transverse and longitudinal LSPR absorption peaks; b optical absorption spectra of $\mathrm{P} 3 \mathrm{HT}: \mathrm{PC}_{61} \mathrm{BM}$ and PCPDTBT:PC ${ }_{71} \mathrm{BM}$ BHJ. Reprinted from Organic Electronics, 14,

both red shifted with respect to the Au NP because of the silica encapsulation. Au-silica NRs dispersed in dichlorobenzene were added to a solution of P3HT and $\mathrm{PC}_{71} \mathrm{BM}$ in the same solvent and spin coated to form the active layer of ITO/PEDOT:PSS/P3HT:PC ${ }_{71} \mathrm{BM} / \mathrm{Ca} / \mathrm{Al}$ devices. Under $100 \mathrm{~mW} / \mathrm{cm}^{2}$ illumination by AM1.5 spectrum, the optimized device with $1 \mathrm{wt} \%$ Au-silica NR in P3HT:PC ${ }_{71} \mathrm{BM}$ active layer has a PCE of $3.58 \%$ which is significantly higher than that of the reference device (3.17\%). The improvement in PCE is mainly due to increase in $J_{\mathrm{sc}}$. However, no change in the $V_{\mathrm{oc}}$ was observed.

Since the absorption spectrum of the P3HT: $\mathrm{PC}_{71} \mathrm{BM}$ blend has a cutoff at $650 \mathrm{~nm}$, it is not well matched to the longitudinal LSPR peak of Au NR at $720 \mathrm{~nm}$ [52]. As a result, $\mathrm{Xu}$ et al. [54] further investigated the PCPDTBT:PC ${ }_{71} \mathrm{BM}$ blend because the low band gap donor PCPDTBT has one of the smallest HOMO-LUMO gap for semiconducting polymers of $1.9 \mathrm{eV}$. When Au-silica NRs were blended into PCPDTBT:PC ${ }_{71} \mathrm{BM}$ at $1 \mathrm{wt} \%$, the PCE increased to $4.4 \%$ compared with $3.5 \%$ for the reference device with the same active layer thickness. The relatively large improvement for this blend was due to both an increase in $J_{\text {sc }}$ and the FF. Like P3HT:PCBM, there was no observable change in $V_{\text {oc }}$.

Solution-processed small molecular (SM) donors are a recent development in the field of OPV. Until recently, most SM donor materials with molecular weight under 1000 are deposited by thermal evaporation. Compared with semiconducting polymers, SM materials have the advantages of mono-dispersity, higher purity and uniformity in device performance from batch to batch. Solution-processable SM donors, therefore, offer the possibility of higher performance BHJ devices. The absorption

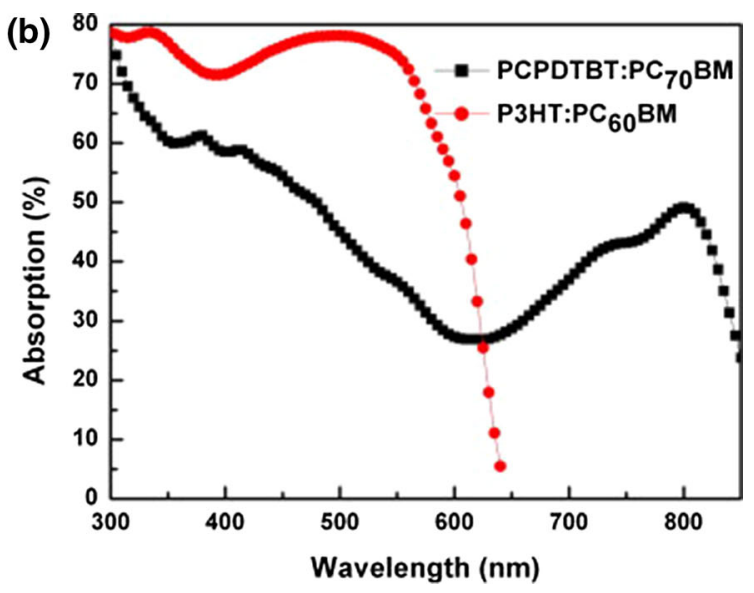

Xiaoyan Xu, Aung K.K. Kyaw, Bo Peng, Terence K.S. Wong, Qihua Xiong, Xiaowei Sun, Alan Heeger, A plasmonically enhanced polymer solar cell with gold-silica core-shell nanorods, 2360-2368, (2013), with permission from Elsevier [52]

enhancement in SM fullerene BHJ devices by $\mathrm{Au}$-silica NRs was demonstrated recently by $\mathrm{Xu}$ et al. [55]. In this study, the molecule 7,7'-(4,4-bis(2-ethylhexyl)-4Hsilolo[3,2-b:4,5-b']-dithiophene-2,6diyl) bis (6-fluoro-4( $5^{\prime}$-hexyl-(2,2'-bithiophen)-5-yl)benzo[c] $(1,2,5)$ thiadia-

zole) (p-DTS $\left(\text { FBTTh }_{2}\right)_{2}$ ) was used as donor in an SM:fullerene BHJ device structure. The NRs have a length and diameter of 89 and $34 \mathrm{~nm}$, respectively, and a silica shell thickness of $6 \mathrm{~nm}$ [55]. When introduced into the active layer of ITO/PEDOT:PSS/p-DTS(FTTh $)_{2}: \mathrm{PC}_{71} \mathrm{BM} / \mathrm{Ca} / \mathrm{Al}$ devices at $1 \mathrm{wt} \%$ of the donor/acceptor, an average PCE of $8.11 \%$ was obtained [55]. This is substantially higher than the reference device without NR $(6.52 \%)$ and the PCE of NR-enhanced polymer fullerene devices studied by the same group. The enhancement is solely due to an increase in $J_{\mathrm{sc}}$. Both $V_{\mathrm{oc}}$ and FF showed no change upon NR incorporation. $\mathrm{Xu}$ et al. also reported the effect of incorporating Au nanospheres into the PEDOT:PSS in addition to $\mathrm{Au}$-silica NR in the active layer. For this configuration, an even higher average PCE of $8.54 \%$ was observed [55].

Since both core shell nanospheres (NS) and NRs can enhance absorption in the active layer of OPV devices, a systematic comparison of the geometric effect of incorporated NPs was made by Xu et al. [56]. In this study, Au NSs with a core diameter of $\sim 25 \mathrm{~nm}$ and a silica shell thickness of $\sim 5 \mathrm{~nm}$ were synthesized. Au NRs with a core diameter and length of $\sim 31$ and $\sim 80 \mathrm{~nm}$ and a shell thickness of $\sim 5 \mathrm{~nm}$ were also prepared [56]. The LSPR peak of the NS and the transverse LSPR peak of the NR are almost the same while the longitudinal peak of the NR is at $680 \mathrm{~nm}$ [56]. These NPs were both incorporated at $1 \mathrm{wt} \%$ into the active layer of two ITO/PEDOT:PSS/pDTS $\left(\mathrm{FBTTh}_{2}\right)_{2}: \mathrm{PC}_{71} \mathrm{BM} / \mathrm{Ca} / \mathrm{Ag}$ devices. For the NS, the PCE of the SM BHJ device increased to $6.86 \%$ compared 
with $6.5 \%$ for the reference. When NRs were similarly introduced, the PCE increased to $8.18 \%$ because of a very significant increase in the $J_{\mathrm{sc}}$. To understand the large difference in enhancement of device performance, a dimensionless quality factor $Q_{\mathrm{LSPR}}$ defined as the ratio of the enhanced localized field around the NP and the incident field was derived and calculated for the NS and NR [56]. For the NS, the $Q_{\mathrm{LSPR}}$ is a weak function of wavelength and is smaller than 25 throughout the spectral range 400-1000 nm. By contrast, the $Q_{\mathrm{LSPR}}$ for NRs increases significantly with wavelength and can exceed 150 for wavelengths from 700 to $1000 \mathrm{~nm}$. This shows that the NR is much more effective in generating enhanced localized fields, especially at wavelengths near the longitudinal LSPR peak. The NRs also scatter light more strongly and increase the optical path length within the active layer. This was demonstrated by measuring the haze factor for diffusely reflected light $\left(H_{\mathrm{R}}\right)$ and transmitted light $\left(H_{\mathrm{T}}\right)$ for p-DTS(FBTTh $)_{2}: \mathrm{PC}_{71}$ BM thin film samples with the two types of NPs. For NS, the film haze factors are almost the same as the reference without NPs from 400 to $800 \mathrm{~nm}$. For NR, both $H_{\mathrm{R}}$ and $H_{\mathrm{T}}$ are significantly higher showing that more light is being scattered by NRs [56].

\section{Ag-silica NP}

Thus far, there has been only one report on Ag core-shell NP blended into the BHJ. In 2013, a high efficiency polymer OPV device containing Ag-silica NP was demonstrated by Choi et al. [57]. The Ag core was synthesized by a polyol process similar to that discussed in section "Ag NP" [49]. After synthesis, the Ag NPs in ethanol were mixed with ammonium hydroxide. Tetraethyl orthosilicate (TEOS), a soluble silica precursor, was then added to the Ag NP solution to form the spherical Agsilica NPs by a sol-gel process. The Ag-silica NPs have a core diameter of about $50 \mathrm{~nm}$ and a silica shell thickness of $10 \mathrm{~nm}$. The absorption spectrum of the NPs in ethanol has an LSPR peak at $450 \mathrm{~nm}$. This is also red shifted relative to Ag NPs of the same diameter because of the silica shell [46]. Ag-silica NPs were introduced to a polymer solar cell consisting of poly\{[4,8bis[(2-ethylhexyl)oxy]benzo[1,2-b4,5-b']dithiophene-2,6-diyl][3-fluoro-2-[(2-ehtylhexyl)carbonyl]-thieno-[3,4,b]thiophenediyl] $\}$ (PTB7) and $\mathrm{PC}_{71-}$ $\mathrm{BM}$. This type II structure is illustrated in Fig. 8a. For an ITO/PEDOT:PSS/Ag-SiO $2 / \mathrm{PTB}_{2}: \mathrm{PC}_{71} \mathrm{BM} / \mathrm{Al}$ structure, a $\mathrm{UV}-\mathrm{V}$ is absorption enhancement was observed relative to the reference device at 400-700 $\mathrm{nm}$ [57]. As a result, the PCE of this device $(8.92 \%)$ was much higher than the reference $(7.26 \%)$ due to a significantly higher $J_{\text {sc }}$. A type I device with the Ag-silica NP introduced at the ITO/PEDOT:PSS interface also has higher PCE than reference.
However, the PCE is lower than the type II device (Fig. 9). Choi et al. also fabricated a device with type II device structure with Ag NPs instead of Ag-silica NPs in contact with the BHJ. The device performance for this device structure was inferior to the device with Ag-silica NPs. This shows that an insulating shell is effective in minimizing exciton quenching effects.

\section{Criteria for designing metallic NP for BHJ incorporation}

Table 1 shows a summary of all the plasmonic OPV devices reviewed in this article. From this review of the recent literature, several observations regarding metallic NPs incorporated into OPV devices can be made. First, the enhancement effects are more effective when these NPs are embedded within or adjacent to the BHJ layer. Second, for direct incorporation into the $\mathrm{BHJ}$ or between the $\mathrm{BHJ}$ and the anode interlayer, Au or Ag NPs with organic ligands should in general be avoided for reasons that have been explained earlier. The main exception to this is the monofunctional PEG ligand. Third, both bare metal NPs formed by the physical laser ablation method or chemically synthesized metal-silica core shell NPs are suitable for incorporation in the BHJ. At moderate concentration, these NPs can increase the PCE of OPV devices by increasing the light absorption via the near field plasmonic effect and/ or the far field light scattering effect. Furthermore, for bare metal NPs in P3HT:PC ${ }_{60} \mathrm{BM}$, both the $J_{\mathrm{sc}}$ and $V_{\mathrm{oc}}$ can be enhanced by the NP incorporation. Although core-shell NPs can also enhance device $J_{\mathrm{sc}}$, the $V_{\mathrm{oc}}$ of the OPV device is not increased and depend only on the donor and acceptor HOMO and LUMO energy levels. The reason for this is not well understood at present and further research will be needed. For a given noble metal, greater benefit can be obtained using larger NPs $(50-100 \mathrm{~nm})$ because the scattering cross section at the LSPR increases rapidly with particle size. For spherical particles, the ratio of the cross section for scattering $C_{\text {sca }}$ to the cross section for absorption $C_{\mathrm{abs}}$ varies with the third power of the particle diameter $d$ as shown by Eq. (1) [17]:

$\frac{C_{\mathrm{sca}}}{C_{\mathrm{abs}}}=\frac{1}{12}\left(\frac{2 \pi n_{\mathrm{m}} d}{\lambda}\right)^{3}\left|\frac{\varepsilon-\varepsilon_{\mathrm{m}}}{\varepsilon+2 \varepsilon_{\mathrm{m}}}\right|^{2}\left[\operatorname{Im}\left(\frac{\varepsilon-\varepsilon_{\mathrm{m}}}{\varepsilon+2 \varepsilon_{\mathrm{m}}}\right)\right]^{-1}$

In the above equation, $n_{\mathrm{m}}$ is the refractive index of the medium surrounding the NP; $\varepsilon$ and $\varepsilon_{\mathrm{m}}$ are the complex dielectric function of the metal and the medium, respectively, and $\lambda$ is the wavelength of light. Hence for very small NPs in the same BHJ medium, only the near field effect can be exploited. Note that the maximum NP size is ultimately limited by the organic film thickness. 
(a)

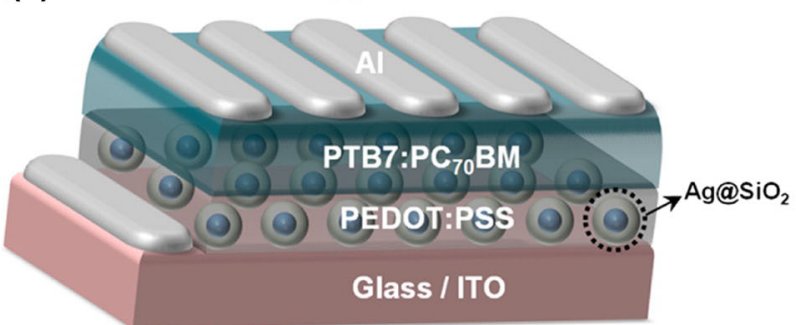

Type II

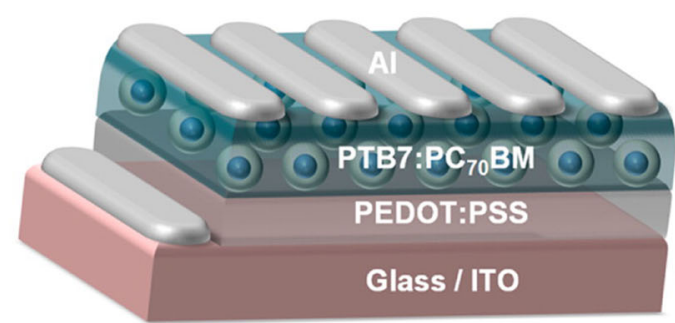

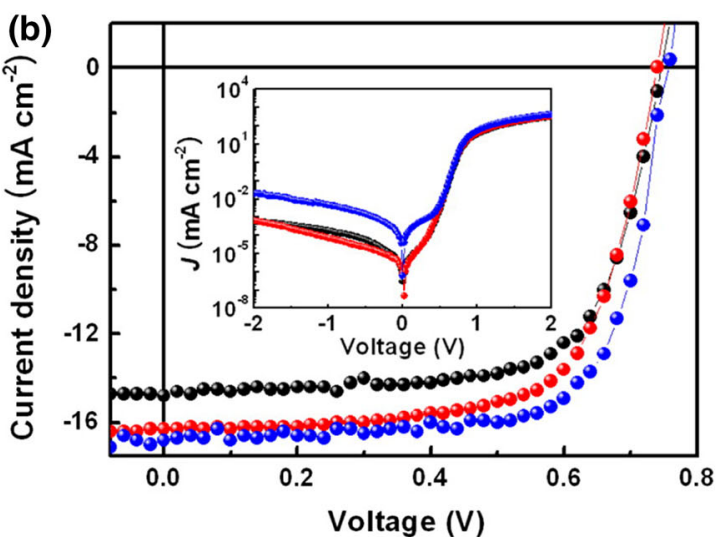

Fig. 9 a Type I and type II F8BT:PC ${ }_{71} \mathrm{BM}$ device with Ag-silica NP incorporated at ITO/PEDOT:PSS and PEDOT:PSS/BHJ interface, respectively; b illuminated $J-V$ characteristics of type I, type II and reference devices and $\mathbf{c}$ external quantum efficiency spectra of type I,

For the core-shell NPs, an additional consideration is the thickness of the dielectric layer. The dielectric layer should be thin enough to allow an enhanced localized field to exist outside the shell layer. However, it should be thick enough to reduce recombination loss. The effect of the dielectric layer thickness of Au-silica NR on small molecule BHJ OPV devices was investigated recently by Xu et al. [58]. The NRs used have silica thickness of 5, 7 and $10 \mathrm{~nm}$ and an average core diameter and length of 34 and $87 \mathrm{~nm}$, respectively [58]. When these NRs were incorporated at $1 \mathrm{wt} \%$ of donor acceptor weight into the active layer of ITO/PEDOT:PSS/ $\mathrm{DTS}(\mathrm{FBTTh})_{2}: \mathrm{PC}_{70} \mathrm{BM} / \mathrm{Ca} / \mathrm{Ag}$ devices, a maximum average PCE of $8.2 \%$ was observed for the $5 \mathrm{~nm}$ silica shell [58]. By comparison, the reference device without NRs has an average PCE of only $6.5 \%$. The PCE for the devices with NRs having 7 and $10 \mathrm{~nm}$ silica shells are both lower than the optimal device. The cause of the better performance of NRs with $5 \mathrm{~nm}$ silica shell is solely due to a higher $J_{\mathrm{sc}}$. Finite difference time domain (FDTD) simulations were carried out to understand the origin of this enhanced photocurrent generation. In the FDTD simulations, the electric field intensity within and in the vicinity of an NR embedded within an organic medium was simulated for polarized light at normal incidence with wavelengths corresponding to the two LSPR wavelengths (520 and $680 \mathrm{~nm}$ ) [58]. The electric field intensity is higher at the surface of the $5 \mathrm{~nm}$ thick silica shell

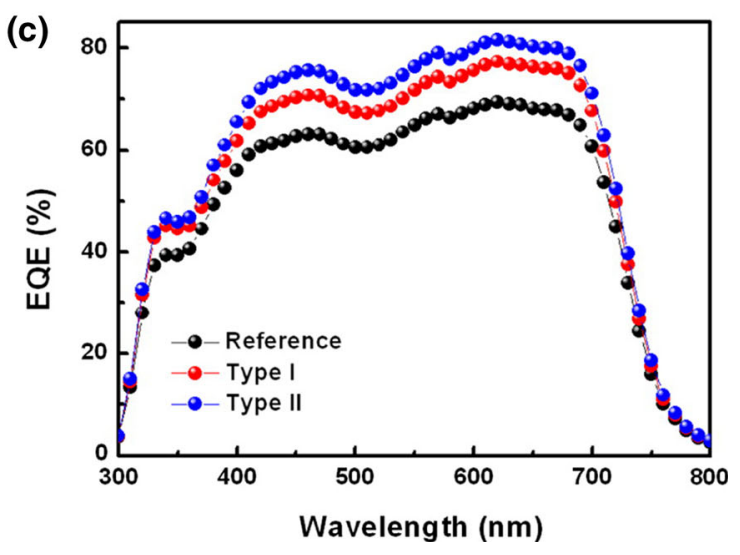

type II and reference devices. Reprinted with permission from Nano Lett. 2013, 13, 2204-2208. Copyright (2013) American Chemical Society [57]

compared with the 7 and $10 \mathrm{~nm}$ silica shell. This indicates that at $5 \mathrm{~nm}$ shell thickness, an enhanced localized field can exist at the BHJ in the vicinity of the NR. This finding is consistent with earlier studies on the effect of dielectric thickness of core-shell NPs in dye sensitized solar cells [59]. $\mathrm{Xu}$ et al. [58] also measured the scattering properties of DTS(FBTTh $)_{2}: \mathrm{PC}_{70} \mathrm{BM}$ films embedded with $\mathrm{Au}$-silica NR with different silica thickness. The silica thickness has little effect on both the diffuse reflectance and transmittance. As a result, the enhanced localized field effect appeared to be the main reason for the improved device performance.

Very recently, by reducing the silica thickness of $\mathrm{Au}-$ silica NR located at the interface between PTB7:PC ${ }_{71} B M$ and PEDOT:PSS to $2.5 \mathrm{~nm}$, Zhang et al. [60] achieved a single junction device PCE of $9.55 \%$. This is currently among the highest reported PCE for plasmonic OPV devices.

\section{Conclusion}

The plasmonic enhancement effects of three types of metallic NPs embedded in the BHJ OPV devices have been reviewed. Metallic NPs with organic ligands may enhance the carrier transport and result in an increased PCE. However, for many polymeric systems, the effect of metallic NPs with organic ligands tends to be negative. The 
Table 1 Summary of reviewed plasmonic OPV devices with NP-incorporated BHJ

\begin{tabular}{|c|c|c|c|c|c|}
\hline $\mathrm{BHJ}$ & NP & NP size $(\mathrm{nm})$ & Highest PCE (\%) & Control PCE (\%) & Reference \\
\hline P3OT: $\mathrm{C}_{60}$ & $\mathrm{Au}-\mathrm{C}_{12} \mathrm{H}_{25} \mathrm{NH}_{2}$ & 5.3 & 1.7 & 1.15 & {$[15]$} \\
\hline $\mathrm{P} 3 \mathrm{HT}: \mathrm{PC}_{61} \mathrm{BM}$ & $\mathrm{Au}-\mathrm{P} 3 \mathrm{HT}$ & 3.7 & 1.5 & 2.5 & {$[27]$} \\
\hline $\mathrm{P} 3 \mathrm{HT}: \mathrm{PC}_{61} \mathrm{BM}$ & $\mathrm{Au}-\mathrm{C}_{12} \mathrm{H}_{25} \mathrm{NH}_{2}$ & 7.0 & 2.9 & 3.2 & {$[27]$} \\
\hline $\mathrm{P} 3 \mathrm{HT}: \mathrm{PC}_{61} \mathrm{BM}$ & $\mathrm{Au}-\mathrm{C}_{5} \mathrm{H}_{5} \mathrm{~N}$ & 15 & 1.1 & 2.4 & {$[27]$} \\
\hline PFSDCN:PC ${ }_{61} \mathrm{BM}$ & $\mathrm{Au}-\mathrm{mPEG}$ & 18 & 2.17 & 1.64 & {$[30]$} \\
\hline $\mathrm{P} 3 \mathrm{HT}: \mathrm{PC}_{61} \mathrm{BM}$ & $\mathrm{Au}-\mathrm{mPEG}$ & 35 & 3.4 & 3.16 & {$[31]$} \\
\hline P3OT: $\mathrm{C}_{60}$ & $\mathrm{Ag}-\mathrm{C}_{12} \mathrm{H}_{25} \mathrm{NH}_{2}$ & 6.1 & 1.9 & 1.15 & {$[15]$} \\
\hline P3HT:PC ${ }_{61} \mathrm{BM}$ & $\mathrm{Ag}-\mathrm{CH}_{3}\left(\mathrm{CH}_{2}\right)_{11} \mathrm{SH}$ & $5-15$ & 3.3 & 3.4 & {$[32]$} \\
\hline $\mathrm{P} 3 \mathrm{HT}: \mathrm{PC}_{61} \mathrm{BM}$ & Ag-carboxylic acid & 3.65 & 1.2 & 2.2 & [34] \\
\hline P3HT:PC ${ }_{61} \mathrm{BM}$ & $\mathrm{Ag}-(\mathrm{COONa})\left(\mathrm{CH}_{2} \mathrm{COONa}\right)_{2}$ & 46.7 & 3.45 & 2.72 & {$[35]$} \\
\hline P3HT:PC 61 BM & $\mathrm{Au}$ & $1.5-40$ & 3.71 & 2.64 & {$[42]$} \\
\hline PCDTBT:PC ${ }_{71} \mathrm{BM}$ & $\mathrm{Au}$ & 70 & 6.45 & 6.11 & {$[46]$} \\
\hline Si-PCPDTBT:PC ${ }_{71} \mathrm{BM}$ & $\mathrm{Au}$ & 70 & 4.54 & 4.28 & [46] \\
\hline P3HT:PC 61 BM & $\mathrm{Ag}$ & 12,23 & 2.65 & 2.41 & [47] \\
\hline PCDTBT:PC ${ }_{71} \mathrm{BM}$ & $\mathrm{Ag}$ & $30-60$ & 7.1 & 6.3 & {$[48]$} \\
\hline P3HT:PC ${ }_{61} \mathrm{BM}$ & $\mathrm{Au}-$ silica & $\begin{array}{l}14(\mathrm{Au}) \\
13 \text { (silica) }\end{array}$ & 2.17 & 1.95 & {$[25]$} \\
\hline P3HT:PC ${ }_{71} \mathrm{BM}$ & $\mathrm{Au}-$ silica & $\begin{array}{l}92.5 / 34.3(\mathrm{Au}) \\
17 \text { (silica) }\end{array}$ & 3.58 & 3.17 & {$[52]$} \\
\hline PCPDTBT:PC ${ }_{71} \mathrm{BM}$ & $\mathrm{Au}-$ silica & $\begin{array}{l}92.5 / 34.3(\mathrm{Au}) \\
17 \text { (silica) }\end{array}$ & 4.4 & 3.5 & {$[52]$} \\
\hline $\mathrm{p}-\mathrm{DTS}\left(\mathrm{FTTh}_{2}\right)_{2}: \mathrm{PC}_{71} \mathrm{BM}$ & $\mathrm{Au}-$ silica & $\begin{array}{l}89 / 34(\mathrm{Au}) \\
6 \text { (silica) }\end{array}$ & 8.11 & 6.52 & {$[55]$} \\
\hline $\mathrm{p}$-DTS $\left(\mathrm{FTTh}_{2}\right)_{2}: \mathrm{PC}_{71} \mathrm{BM}$ & Au-silica & $\begin{array}{l}25(\mathrm{Au}) \\
5 \text { (silica) }\end{array}$ & 6.86 & 6.5 & {$[56]$} \\
\hline PTB7:PC ${ }_{71} \mathrm{BM}$ & Ag-silica & $\begin{array}{l}50(\mathrm{Ag}) \\
10 \text { (silica) }\end{array}$ & 8.92 & 7.26 & {$[57]$} \\
\hline PTB7:PC ${ }_{71} \mathrm{BM}$ & Au-silica & $\begin{array}{l}\sim 30 / 15(\mathrm{Au}) \\
3(\text { silica })\end{array}$ & 9.55 & 7.52 & {$[60]$} \\
\hline
\end{tabular}

causes of reduced PCE include exciton quenching, carrier trapping and recombination. For enhancement of PCE, either bare metal NPs or core shell NPs with a dielectric outer shell can be incorporated in the BHJ. The enhancement mechanisms include the strong localized fields around the NP and increased far field light scattering at the LSPR. For both bare metal and core shell NPs, the size and morphology should be carefully selected. Larger NR particles appear to be especially suitable for plasmonic enhancement. Finally, for core shell NPs in particular, the thickness of the dielectric shell is a crucial design parameter and should be synthesized at optimal thickness.

Open Access This article is distributed under the terms of the Creative Commons Attribution 4.0 International License (http:// creativecommons.org/licenses/by/4.0/), which permits unrestricted use, distribution, and reproduction in any medium, provided you give appropriate credit to the original author(s) and the source, provide a link to the Creative Commons license, and indicate if changes were made.

\section{References}

1. Tang, Z., Tress, W., Inganas, O.: Light trapping in thin film organic solar cells. Mater. Today 17, 389-396 (2014)

2. Catchpole, K.R., Mokkapati, S., Beck, F., Wang, E.-C., McKinley, A., Basch, A., Lee, J.: Plasmonics and nanophotonics for photovoltaics. MRS Bull. 36, 461-467 (2011)

3. Pluchery, O.: Optical properties of gold nanoparticles. In: Louis, C., Pluchery, O. (eds.) Gold Nanoparticles for Physics, Chemistry and Biology, pp. 43-74. Imperial College Press, London (2012)

4. Pillai, S., Green, M.A.: Plasmonics for photovoltaic applications. Sol. Energy Mater. Sol. Cells 94, 1481-1486 (2010)

5. Haes, A.J., Haynes, C.L., McFarland, A.D., Schatz, G.C., Van Duyne, R.P., Zou, S.: Plasmonic materials for surface-enhanced sensing and spectroscopy. MRS Bull. 30, 368-375 (2005)

6. Polman, A., Knight, M., Garnett, E.C., Ehrler, B., Sinke, W.C.: Photovoltaic materials: present efficiencies and future challenges. Science 352, aad4424 (2016)

7. Jacoby, M.: Commercializing Low-Cost Solar Cells. Chem. Eng., News (2016)

8. He, Z.C., Xiao, B., Liu, F., Wu, H.B., Yang, Y.L., Xiao, S., Wang, C., Russell, T.P., Cao, Y.: Single-junction polymer solar 
cells with high efficiency and photovoltage. Nat. Photonics 9, 174-179 (2015)

9. Gan, Q., Bartoli, F.J., Kafafi, Z.H.: Plasmonic-enhanced organic photovoltaics: breaking the $10 \%$ efficiency barrier. Adv. Mater. 25, 2385-2396 (2013)

10. Hoppe, H., Sariciftci, N.S.: Organic solar cells: an overview. J. Mater. Res. 19, 1924-1945 (2004)

11. Forrest, S.R.: The limits to organic photovoltaic cell efficiency. MRS Bull. 30, 28-32 (2005)

12. Stuart, H.R., Hall, D.G.: Absorption enhancement in silicon-oninsulator waveguide using metal island films. Appl. Phys. Lett. 69, 2327-2329 (1996)

13. Pillai, S., Catchpole, K.R., Trupke, T., Green, M.A.: Surface plasmon enhanced silicon solar cells. J. Appl. Phys. 101, 093105 (2007)

14. Catchpole, K.R., Polman, A.: Plasmonic solar cells. Opt. Exp. 16, 21793-21800 (2008)

15. Kim, K., Carroll, D.L.: Roles of $\mathrm{Au}$ and $\mathrm{Ag}$ nanoparticles in efficiency enhancement of poly(3-octylthiophene)/ $\mathrm{C}_{60}$ bulk heterojunction photovoltaic devices. Appl. Phys. Lett. 87, 203113 (2005)

16. Stratakis, E., Kymakis, E.: Nanoparticle-based plasmonic organic photovoltaic devices. Mater. Today 16, 133-146 (2013)

17. Yu, E.T.: Nanoplasmonics for photovoltaic applications. In: Tsakalakos, L. (ed.) Nanotechnology for Photovoltaics, pp. 391-421. CRC Press, Boca Raton (2010)

18. Li, X., Choy, W.C.H., Lu, H., Sha, W.E.I., Ho, A.H.P.: Efficiency enhancement of organic solar cells by using shape-dependent broadband plasmonic absorption in metallic nanoparticles. Adv. Funct. Mater. 23, 2728-2735 (2013)

19. Heo, M., Cho, H., Jung, J.-W., Jeong, J.-R., Park, S., Kim, J.Y.: High-performance organic optoelectronic devices enhanced by surface plasmon resonance. Adv. Mater. 23, 5685-5693 (2011)

20. Li, X., Choy, W.C.H., Huo, L., Xie, F., Sha, W.E.I., Ding, B., Guo, X., Li, Y., Hou, J., You, J., Yang, Y.: Dual plasmonic nanostructures for high performance inverted organic solar cells. Adv. Mater. 24, 3045-3052 (2012)

21. Morfa, A.J., Rowlen, K.L., Reilly, T.H., Romero, M.J., van de Lagemaat, J.: Plasmon-enhanced solar energy conversion in organic bulk heterojunction photovoltaics. Appl. Phys. Lett. 92, 013504 (2008)

22. Chen, F.C., Wu, J.L., Lee, C.L., Hong, Y., Kuo, C.H.: Plasmonicenhanced polymer photovoltaic devices incorporating solutionprocessable metal nanoparticles. Appl. Phys. Lett. 95, 013305 (2009)

23. Wu, J.L., Chen, F.C., Hsiao, Y.S., Chien, F.C., Chen, P., Kuo, C.H., Huang, M.H., Hsu, C.S.: Surface plasmonic effects of metallic nanoparticles on the performance of polymer bulk heterojunction solar cells. ACS Nano 2, 959-967 (2011)

24. Lee, J.-Y., Peumans, P.: The origin of enhanced optical absorption in solar cells with metal nanoparticles embedded in the active layer. Opt. Exp. 18, 10078-10087 (2010)

25. Huang, Y.-F., Zhang, Z.-L., Kang, K.-B., Zhao, M., Wen, T., Liu, Y.-X., Zhai, X.-P., Lv, S.-K., Wang, Q., Qiu, W.-Y., Qiu, D.: Mitigation of metal-mediated losses by coating Au nanoparticles with dielectric layer in plasmonic solar cells. RSC Adv. 3, 16080-16088 (2013)

26. Leff, D.V., Brandt, L., Heath, J.R.: Synthesis and characterization of hydrophobic, organically-soluble gold nanocrystals functionalized with primary amines. Langmuir 12, 4723-4730 (1996)

27. Topp, K., Borchert, H., Johnen, F., Tunc, A.V., Knipper, M., von Hauff, E., Parisi, J., Al-Shamery, K.: Impact of incorporation of $\mathrm{Au}$ nanoparticles into polymer/fullerene solar cells. J. Phys. Chem. A 114, 3981-3989 (2010)
28. Zhai, L., McCullough, R.D.: Regioregular polythiophene/gold nanoparticle hybrid materials. J. Mater. Chem. 14, 141-143 (2004)

29. Jana, N.R., Peng, X.: Single-phase and gram-scale routes towards nearly monodisperse $\mathrm{Au}$ and other noble metal nanocrystals. J. Am. Chem. Soc. 125, 14280-14281 (2003)

30. Wang, C.C.D., Choy, W.C.H., Duan, C., Fung, D.D.S., Sha, W.E.I., Xie, F.-X., Huang, F., Cao, Y.: Optical and electrical effects of gold nanoparticles in the active layer of polymer solar cells. J. Mater. Chem. 22, 1206-1211 (2012)

31. Xie, F.-X., Choy, W.C.H., Wang, C.C.D., Sha, W.E.I., Fung, D.D.S.: Improving the efficiency of polymer solar cells by incorporating nanoparticles into all polymer layers. Appl. Phys. Lett. 99, 153304 (2011)

32. Xue, M., Li, L., Tremolet de Villers, B.J., Shen, H., Zhu, J., Yu, Z., Steig, A.Z., Pei, Q., Schwartz, B.J., Wang, K.L.: Chargecarrier dynamics in hybrid plasmonic organic solar cells with $\mathrm{Ag}$ nanoparticles. Appl. Phys. Lett. 98, 253302 (2011)

33. Pivrikas, A., Sariciftci, N.S., Juska, G., Osterbacka, R.: A review of charge transport and recombination in polymer/fullerene organic solar cells. Prog. Photovolt. Res. Appl. 15, 677-696 (2007)

34. Yoon, W.-J., Jung, K.-Y., Liu, J., Duraisamy, T., Revur, R., Teixeira, F.L., Sengupta, S., Burger, P.R.: Plasmon-enhanced optical absorption and photocurrent in organic bulk heterojunction photovoltaic devices using self-assembled layer of silver nanoparticles. Sol. Energy Mater. Sol. Cells 94, 128-132 (2010)

35. Pei, J., Tao, J., Zhou, Y., Dong, Q., Liu, Z., Li, Z., Chen, F., Zhang, J., Xu, W., Tian, W.: Efficiency enhancement of polymer solar cells by incorporating a self-assembled layer of silver nanodisks. Sol. Energy Mater. Sol. Cells 95, 3281-3286 (2011)

36. Tang, B., Xu, S.P., An, J., Zhao, B., Xu, W.Q.: Photoinduced shape conversion and reconstruction of silver nanoprisms. J. Phys. Chem. C 113, 7025-7030 (2009)

37. Chen, H.-C., Chou, S.-W., Tseng, W.-H., Chen, I.-W.P., Liu, C.C., Liu, C., Liu, C.-L., Chen, C.-H., Wu, C.-I., Chou, P.T.: Large $\mathrm{AuAg}$ alloy nanoparticles synthesized in organic media using a one-pot reaction: their applications for high-performance bulk heterojunction solar cells. Adv. Funct. Mater. 22, 3975-3984 (2012)

38. Green, M.: Semiconductor Quantum Dots: Organometallic and Inorganic Synthesis. Royal Society of Chemistry, London (2014)

39. Noone, K.M., Ginger, D.S.: Charge and energy transfer in polymer/nanocrystal blends. In: Konstantatos, G., Sargent, E.H. (eds.) Colloidal Quantum Dot Optoelectronics and Photovoltaics, pp. 87-111. Cambridge University Press, Cambridge (2013)

40. Munro, A.M.: Selenide and sulfide quantum dots and nanocrystals: optical properties. In: Bergman, L., McHale, J.L. (eds.) Handbook of Luminescent Semiconductor Materials, pp. 307-320. CRC Press, Boca Raton (2011)

41. Bera, D., Qian, L., Holloway, P.H.: Phosphor quantum dots. In: Kitai, A. (ed.) Luminescent Materials and Applications, pp. 19-73. Wiley, New York (2008)

42. Spyropoulos, G.D., Stylianakis, M.M., Stratakis, E., Kymakis, E.: Organic bulk heterojunction photovoltaic devices with surfactantfree Au nanoparticles embedded in the active layer. Appl. Phys. Lett. 100, 213904 (2012)

43. Stratakis, E., Zorba, V., Barberoglou, M., Fotakis, C., Shafeev, G.A.: Laser writing of nanostructures on bulk $\mathrm{Al}$ via its ablation in liquids. Nanotechnology 20, 105303 (2009)

44. Paic, B., Spyropoulos, G.D., Generosi, A., Bailo, D., Albertini, V.R., Stratakis, E., Kymakis, E.: Enhanced structural stability and performance durability of bulk heterojunction photovoltaic devices incorporating metallic nanoparticles. Adv. Funct. Mater. 21, 3573-3582 (2011) 
45. Blouin, N., Michaud, A., Leclerc, M.: A low-bandgap poly(2,7carbazole) derivative for use in high-performance solar cells. Adv. Mater. 19, 2295-2300 (2007)

46. Wang, D.H., Kim, D.Y., Choi, K.W., Seo, J.H., Im, S.H., Park, J.H., Park, O.O., Heeger, A.J.: Enhancement of donor-acceptor polymer bulk heterojunction solar cell power conversion efficiencies by addition of $\mathrm{Au}$ nanoparticles. Angew. Chem. Int. Ed. 50, 5519-5523 (2011)

47. Kalfagiannatis, N., Karagiannidis, P.G., Pitsalidis, C., Panagiotopoulos, N.T., Gravalidis, C., Kassavetis, S., Patsalas, P., Logothetidis, S.: Plasmonic silver nanoparticles for improved organic solar cells. Sol. Energy Mater. Sol. Cells 104, 163-174 (2012)

48. Wang, D.H., Park, K.H., Seo, J.H., Seifter, J., Jeon, J.H., Kim, J.K., Park, J.H., Park, O.O., Heeger, A.J.: Enhanced power conversion efficiency in $\mathrm{PCDTBT} / \mathrm{PC}_{70} \mathrm{BM}$ bulk heterojunction photovoltaic devices with embedded silver nanoparticle clusters. Adv. Energy Mater. 1, 766-770 (2011)

49. Yu, C.H., Tam, K., Tsang, E.S.C.: Chemical methods for preparation of nanoparticles in solution. In: Blackman, J.A. (ed.) Metallic Nanoparticles, pp. 113-141. Elsevier, Amsterdam (2009)

50. Xu, X.: Plasmonic organic solar cells with gold nanoparticles. $\mathrm{PhD}$ Thesis (2015)

51. Perez, J.P., Pastoriza-Santos, I., Liz-Marzan, M., Mulvany, P.: Gold nanorods: synthesis, characterization and applications. Coord. Chem. Rev. 249, 1870-1901 (2005)

52. Xu, X., Kyaw, A.K.K., Peng, B., Zhao, D., Wong, T.K.S., Xiong, Q., Sun, X.W., Heeger, A.J.: A plasmonically enhanced polymer solar cell with gold-silica core-shell nanorods. Org. Electron. 14, 2360-2368 (2013)

53. Link, S., Mohammed, M.B., El-Sayed, M.A.: Simulation of the optical absorption spectra of gold nanorods as a function of their aspect ratio and the effect of the medium dielectric constant. J. Phys. Chem. B 103, 3073-3077 (1999)

54. Muhlbacher, D., Scharber, M., Morana, M., Zhu, Z., Waller, D., Gaudiana, R., Brabec, C.: High photovoltaic performance of a low-bandgap polymer. Adv. Mater. 18, 2884-2889 (2006)

55. Xu, X., Kyaw, A.K.K., Peng, B., Du, Q., Hong, L., Demir, H.V., Wong, T.K.S., Xiong, Q., Sun, X.W.: Enhanced efficiency of solution-processed small-molecule solar cells upon incorporation of gold nanospheres and nanorods into organic layers. Chem. Commun. 50, 4451-4454 (2014)

56. Xu, X., Kyaw, A.K.K., Peng, B., Xiong, Q., Demir, H.V., Wang, Y., Wong, T.K.S., Sun, X.W.: Influence of gold-silica nanoparticle on the performance of small-molecule bulk heterojunction solar cells. Org. Electron. 22, 20-28 (2015)

57. Choi, H., Lee, J.-P., Ko, S.-J., Jung, J.-W., Park, H., Yoo, S., Park, O., Jeong, J.-R., Park, S., Kim, J.Y.: Multipositional silicacoated silver nanoparticles for high-performance polymer solar cells. Nano Lett. 13, 2204-2208 (2013)

58. Xu, X., Du, Q., Peng, B., Xiong, Q., Hong, L., Demir, H.V., Wong, T.K.S., Kyaw, A.K.K., Sun, X.W.: Effect of thickness on small-molecule solar cells enhanced by dual plasmonic goldsilica nanorods. Appl. Phys. Lett. 105, 113306 (2014)

59. Brown, M.D., Suteewong, T., Kumar, R.S.S., D'Innocenzo, V., Petrozza, A., Lee, M.M., Wiesner, U., Snaith, H.J.: Plasmonic dye-sensitized solar cells using core-shell metal-insulator nanoparticles. Nano Lett. 11, 438-445 (2011)

60. Zhang, R., Zhou, Y., Peng, L., Chen, C., Feng, X., Guan, Y., Huang, W.: Influence of $\mathrm{SiO}_{2}$ shell thickness on power conversion efficiency in plasmonic polymer solar cells with $\mathrm{Au}$ nanorod@ $\mathrm{SiO}_{2}$ core-shell thickness. Sci. Rep. 6, 25036 (2016) 